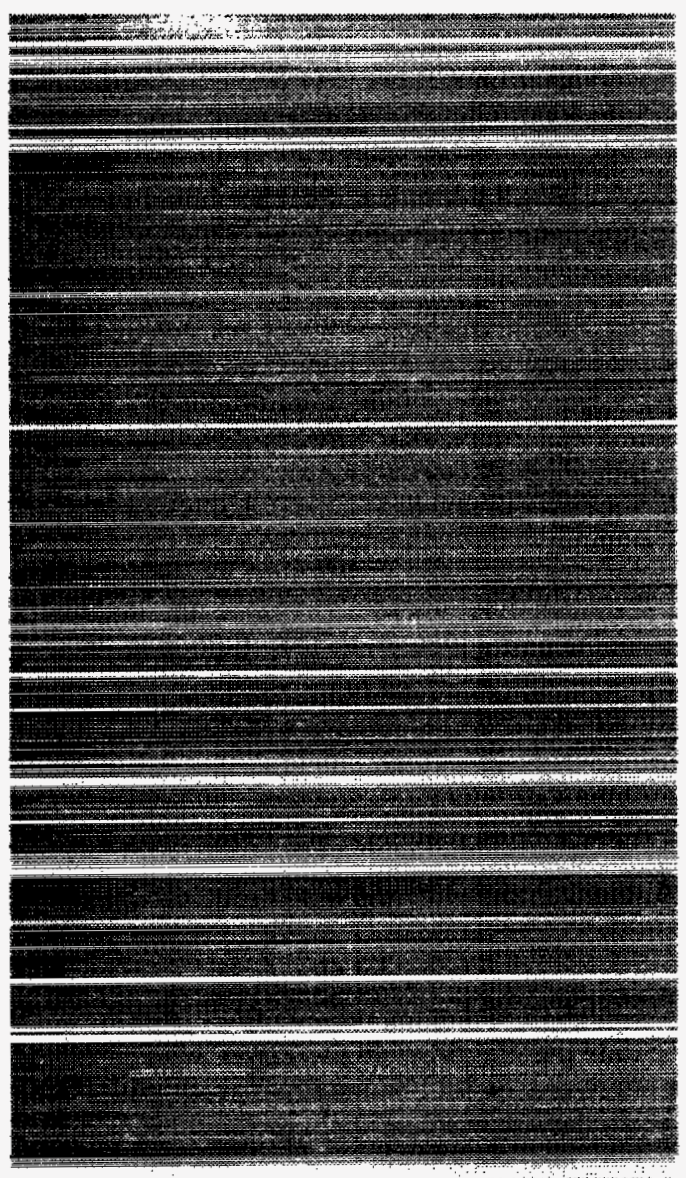

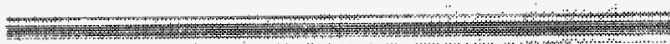

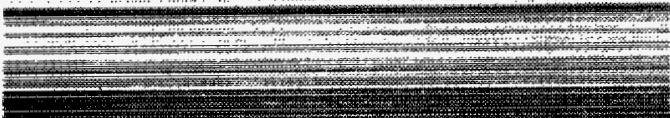
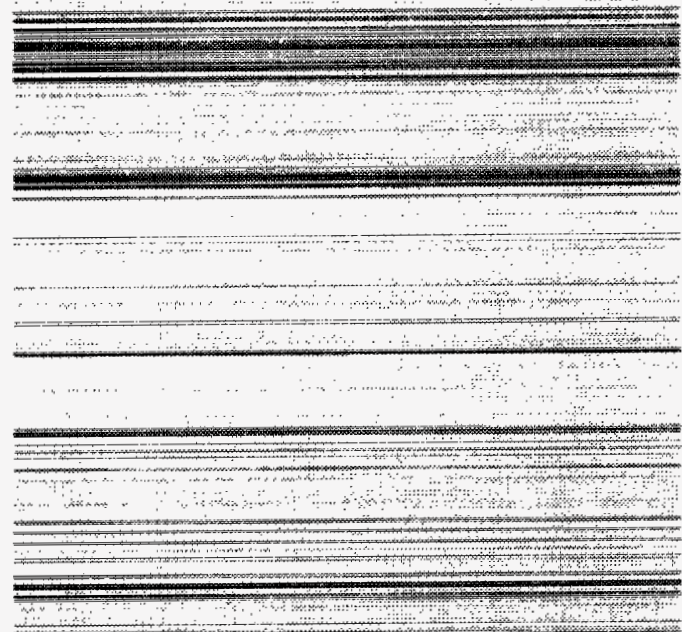

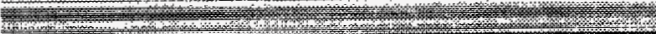
(5)

\section{National Ignition Facility Final Optics}

Assembly Thermal Effects of Maintenance

\section{Operations}

MASTER

DISTRIBUTION OF THIS DOCUMENT IS UNLMITED

\section{Los Alamos \\ NATIONAL LABORATORY}

Los Alamos National Laboratory is operated by the University of California for the United States Department of Energy under contract W-7405-ENG-36. 
An Affirmative Action/Equal Opportunity Employer

This report was prepared as an account of work sponsored by an agency of the United States Government. Neither The Regents of the University of California, the United States Government nor any agency thereof, nor any of their employees, makes any warranty, express or implied, or assumes any legal liability or responsibility for the accuracy, completeness, or usefulness of any information, apparatus, product, or process disclosed, or represents that its use would not infringe privately owned rights. Reference herein to any specific commercial product, process, or service by trade name, trademark, manufacturer, or otherwise, does not necessarily constitute or imply its endorsement, recommendation, or favoring by The Regents of the University of California, the United States Government, or any agency thereof. The views and opinions of authors expressed herein do not necessarily state or reflect those of The Regents of the University of California, the United States Government, or any agency thereof. Los Alamos National Laboratory strongly supports academic freedom and a researcher's right to publish; as an institution, however, the Laboratory does not endorse the viewpoint of a publication or guarantee its technical correctness. 


\section{DISCLAIMER}

Portions of this document may be illegible electronic image products. Images are produced from the best available original document. 
National Ignition Facility Final Optics Assembly Thermal Effects of Maintenance Operations

\section{Lucie Parietti}

Richard A. Martin 


\title{
National Ignition Facility Final Optics Assembly \\ Thermal Effects of Maintenance Operations
}

by

\author{
Lucie Parietti and Richard A. Martin
}

\begin{abstract}
The National Ignition Facility (NIF), the world's most powerful laser system, is being built at Lawrence Livermore National Laboratory (LLNL) to study inertial fusion and high-energydensity science. This billion-dollar facility consists of 192 beams focusing $1.8 \mathrm{MJ}$ on a fusion target.

The Final Optics Assembly (FOA), the last mechanical apparatus before the target chamber, converts the light from an incoming frequency of $1 \omega$ to a target-ready $3 \omega$, and focuses the laser beam. The performance of the frequency conversion crystals is very sensitive to temperature changes; crystal temperature must be maintained within a $0.1^{\circ} \mathrm{C}$ of a nominal temperature prior to a laser shot. Maximizing system availability requires minimizing thermal recovery times after thermal disturbances occurring in both normal and maintenance operations. To guide the design, it is important to have estimates of those recovery times. This report presents Computational Fluid Dynamics (CFD) design calculations to evaluate thermal effects of maintenance operations.
\end{abstract}




\section{INTRODUCTION}

The National Ignition Facility (NIF), the world's most powerful laser system, is being built at Lawrence Livermore National Laboratory (LLNL) for the U.S. Department of Energy to study inertial fusion and high-energy-density science. This billion-dollar facility consists of 192 beams focusing $1.8 \mathrm{MJ}$ on a fusion target.

The Final Optics Assembly (FOA), the last mechanical apparatus before the 11-meterdiameter target chamber, converts the light from an incoming frequency of $1 \omega$ to a target-ready $3 \omega$ and focuses the laser beam. There are 48 FOAs, one per cluster of four beams as shown in Fig. 1. Each FOA is evacuated (during normal operation) and consists of four Integrated Optics Modules (IOMs). Each IOM houses two potassium dihydrogen phosphate (KDP) frequency conversion crystals, the Single Harmonic Generator (SHG) crystal and the Triple Harmonic Generator (THG) crystal, as well as the final focus lens and additional optics. Figure 2 shows a cutaway view of a typical FOA, with a laser beam passing through an IOM as well as a cross section of an IOM.

Temperature control of the KDP crystals is a primary concern; for an eight hour shot sequence, the temperatures of the crystals must be back within the operating range $\left(19.7^{\circ} \mathrm{C}\right.$ to $20.3^{\circ} \mathrm{C}$ ) within seven hours after a laser shot. In addition, temperature variations during the last hour before the next shot cannot exceed $\pm 0.1^{\circ} \mathrm{C}$. Maximizing system availability requires minimizing thermal recovery times after thermal disturbances occurring in both normal and maintenance operations. To guide the design, it is important to have estimates of those recovery times.

Under normal operation (laser shot), the NIF FOA is evacuated. Each FOA needs to be vented to atmospheric pressure before any maintenance operation can be performed and evacuated before a shot can take place. Venting and pump-down of an FOA cause heating and cooling of the gas by adiabatic compression and adiabatic expansion, respectively. It is, therefore, necessary to know the recovery time for the FOA to return to operating temperature before the system is available following a maintenance operation. The purpose of this study is to simulate the thermal upset of the KDP crystals as well as the pressure and flow fields inside the FOA during venting and pump-down. A Computational Fluid Dynamics (CFD) code, CFX, is 
used to predict the temperature, pressure and flow fields inside the FOA during those maintenance operations.

\section{NUMERICAL TOOL}

The CFD code used in this study, CFX, is a mature, full-physics, industry-driven, commercial computer code that has been developed under ISO 9001 requirements and validated with numerous test problems. CFX is a British code and is available in the U.S. from AEA Technologies, Bethel Park, PA.

CFX is a finite-volume, implicit, Navier-Stokes solver that uses a revised version of the Semi-Implicit Method for Pressure-Linked Equations (SIMPLE) technique for the solution of three-dimensional parabolic flows (Patankar, 1980). This revised SIMPLE algorithm was developed by Van Doormal and Raithby and is called SIMPLEC (Van Doormal and Raithby, 1984). In addition, CFX uses several well-developed differencing schemes to discretize the governing differential equations.

All models were generated using Meshbuild, a standard CFX mesh generator that uses a multi-block scheme with a body-fitted grid structure.

\section{PUMP-DOWN AND VENTING SCENARIOS}

Each FOA consists of four similar subassemblies designated as IOMs. Only one of these modules (located in the north-east corner) is modeled, and appropriate boundary conditions are used to account for symmetries with the other three modules. In addition, the IOM design is modular; each IOM contains two separate modules bolted to one another, the Optics Module (containing the vacuum window, the Final Optic Cell designated as FOC, and the alignment motors), and the Debris Shield Module, as shown in Fig. 3. In the probable FOA final design, a kapton membrane isolates the Optics Module from the Debris Shield Module (see Fig. 3). A 10 Torr pressure differential between modules helps prevent particles located below the debris shield from migrating towards the Optics Module. For this reason, the volume located above the Debris Shield Module is designated as the clean volume, while the volume located below it is designated as the contaminated volume as shown in Fig. 3.

During venting or pump-down of the FOA, the four clean volumes and the contaminated volume will be simultaneously vented to atmospheric pressure or evacuated. 
An FOA will be vented in approximately 10 minutes (rather than a few seconds) by slowly opening a control valve. This slow venting should help reduce high-speed flow inside the Optics Module.

During the FOA vacuum pump-down, the 5 volumes mentioned above will be evacuated from atmospheric pressure down to $10^{-3}$ Torr. The one way valve (not shown) separating the 3- $\omega$ calorimetry chamber from the target chamber will then be opened, and the additional gas load coming from the 3- $\omega$ chamber will be absorbed by the target chamber vacuum system at $10^{-6}$ Torr. A slow pump-down is preferred from a cleanliness standpoint, and the effects of a 10 minute pump-down are investigated in this study.

\section{MODEL GEOMETRY AND MATERIAL PROPERTIES}

As the four clean volumes and the contaminated volume are evacuated simultaneously, only a single clean volume (Optics Module) needs to be modeled to investigate the thermal upset caused by a slow pump-down. The pump-down model therefore consists of the clean volume from the vacuum window to the mid-flange as shown on Fig. 3. The debris shield cassette is not included in the model since we are not interested in predicting the thermal upset in this area, and including this cassette would make the flow field more complicated to solve.

All optics components are modeled as flat rectangular plates as shown in Fig. 4. Those optics are supported by a moveable aluminum frame with open top and open bottom. This aluminum frame is designated as the Final Optic Cell (FOC) frame. In the model, contact resistances between the FOC frame and its optics components are estimated based on simple hand calculations, accounting for contributions from conduction (both directly from the optics to the frame and through the silastic mount) and radiative heat transfer through the small evacuated gap around the edges of the optics. Contact resistances of $0.025 \mathrm{~m}^{2} \mathrm{~K} / \mathrm{W}, 0.05 \mathrm{~m}^{2} \mathrm{~K} / \mathrm{W}$, and $0.025 \mathrm{~m}^{2} \mathrm{~K} / \mathrm{W}$ are used for the SHG, the THG, and the final lens, respectively. Circular corner channels are cut in the FOC frame to evacuate air between optics components. These corner channels are modeled as square channels of the same area as the circular ones. Alignment stepping motors are omitted in the model since these motors are assumed to constitute a poor conduction path. Since those stepping motors are not completely closed to flow, they are not believe to influence significantly the flow patterns, either.

For the pump-down model, a square $22 \mathrm{~mm} \times 22 \mathrm{~mm}$ port, located in the center of the east wall and at a vertical location close to the flange, is used as an outlet for this pump-down 
simulation. This port has the same cross-section area as a circular $25 \mathrm{~mm}$ port. For the venting simulation, a square $11 \mathrm{~mm} \times 11 \mathrm{~mm}$ port (same area as a $12 \mathrm{~mm}$ port), centered on the east wall and close to the vacuum window was selected as an inlet.

The thermal properties input in the model for the various Optics Module components are summarized in Table 1. For the final focus lens, typical properties for fused quartz are used. All optics components are assumed to be specular, while the Optics Module housing and the FOC frame are assumed to be $50 \%$ diffuse.

Table 1. Optics Module Components Material Properties

\begin{tabular}{|c|c|c|c|c|}
\cline { 2 - 5 } \multicolumn{1}{c|}{} & $\begin{array}{c}\text { Density } \\
\left(\mathbf{k g} / \mathbf{m}^{3}\right)\end{array}$ & $\begin{array}{c}\text { Specific heat } \\
(\mathbf{J} / \mathbf{k g ~ K})\end{array}$ & $\begin{array}{c}\text { Conductivity } \\
(\mathbf{W} / \mathbf{m ~ K})\end{array}$ & Emissivity \\
\hline Aluminum & 2707.00 & 896.00 & 204.00 & 0.02 \\
\hline Fused quartz & 2200.00 & 686.00 & 1.36 & 0.75 \\
\hline KDP crystals & 2355.00 & 860.00 & 1.90 & 0.86 \\
\hline
\end{tabular}

\section{PUMP-DOWN MODEL}

\section{Grid and Boundary Conditions}

The entire 3-D grid contains a total of 96,000 cells (see Fig. 5). A discrete Shah radiation model (Shah, 1979) with 1,850 zones was generated to solve the radiation heat transfer contribution. A maximum of $4 \times 4 \times 4$ cells per radiation zone was used.

For this study, the operating temperature of the crystals is assumed to be $20^{\circ} \mathrm{C}$. The north and east walls of the Optics Module housing, surrounded by a water cooling jacket, are set at $20.00^{\circ} \mathrm{C}$, while the south and west walls are assumed adiabatic. The top of the Optics Module, which sees ambient temperature, is set to $20.00^{\circ} \mathrm{C}$ as well. Since both clean and contaminated volumes are evacuated at the same time, it is unlikely that the debris shield will give off or receive heat to its surroundings, so the bottom surface of the clean volume is, therefore, assumed to be adiabatic. Initially, the air inside the clean volume is assumed to be at $20.00^{\circ} \mathrm{C}$.

Note that design details for the evacuation circuit and pumps were not settled in time for this simulation. To simulate a 10 minute pump-down, we simply assume an exponential pressure drop at the outlet corresponding to a volumetric pump, neglecting temperature variations in the gas and any pressure drop between the Optics Module and the pump. 


\section{Problem Physics and Solver Parameters}

The physics of this problem are very complicated. The flow field is expected to be and is therefore treated as a 3-D, transient, fully compressible, laminar, buoyant flow of a perfect gas.

The flow field is compressible since the density of the gas is dropping as mass is evacuated from the clean volume. The continuum equations are valid as long as the molecular mean free path is smaller than the characteristic length of the Optics Module (Roth, 1982), which is true as long as the pressure does not drop below $7.8 \times 10^{-5}$ Torr. Therefore, since the Optics Module is only evacuated to $10^{-3}$ Torr, the continuum flow equations are appropriate to describe the gas behavior. In addition, as long as the pressure is higher than the range of rarefied gas flow, the viscosity as well as the thermal conductivity of a gas is independent of pressure. In this study, the gas properties within each cell vary as a function of the gas temperature only.

Note that laminar heat transfer prevails on all surfaces except in the outlet region. For this reason, the flow is assumed laminar to accurately predict the cooling of the crystals.

All three modes of heat transfer, conduction, convection, and radiation, have to be taken into account. Initially, convection is the dominant mode of heat transfer. During the first five seconds, forced convection dominates. Next, free convection overcomes forced convection as the temperature of the gas drops rapidly because of the expansion process and as the crystal temperatures lag behind. The temperature of the gas reaches a minimum and starts to warm back-up as natural convection overtakes the expansion cooling. The convection will eventually die out as the temperature differences between the crystals and the gas decrease and as the gas becomes less dense. At some point, convection will be negligible compared to conduction in the gas and radiation heat transfer. Conduction and radiation will ultimately cause temperature recovery of the crystals.

When convection becomes negligible compared to other heat transfer modes, the flow equations no longer have to be solved and the problem can be run as a coupled radiationconduction problem. This allows the CFX code to take bigger time steps than was possible when the flow field was being solved.

Because the solution needs to be time-accurate for each time step, a severe convergence criteria based on the residuals was set. To provide an indication of convergence as the solution evolves, residuals are computed at each time step in each cell of the mesh. Each dependent variable, $y$, is solved for in algebraic equations of the form

$$
f(y)=F,
$$


where $\mathrm{F}$ is a forcing function. The global residual for the variable $\mathrm{y}$ is the absolute difference between the left-hand side and the right-hand side of this equation, summed over the whole grid.

As the flow equations were solved, the convergence criteria was that the sum of the enthalpy residuals (for all the domain cells) divided by the total enthalpy leaving the system as well as the sum of the mass residuals divided by the total mass leaving the system was less than $1 \%$. To meet this convergence criteria, very small time steps (between $0.02 \mathrm{~s}$ and $0.04 \mathrm{~s}$ ) were taken, with an average of 40 iterations per time step. Because of these very small time steps, the problem was very CPU (Central Processing Unit) time intensive. It took three months on a DEC Alpha workstation ( $1 \mathrm{~Gb}$ RAM - $500 \mathrm{MHz}$ ) to run the first three minutes of the pump-down. For the conduction-radiation solution, no flow was leaving the system so the convergence criteria had to be modified. The ratio of the sum of the enthalpy residuals over the total heat dissipated in the system had to be smaller than $1 \%$. During that phase of the run, the time step used was increased from $0.02 \mathrm{~s}$ to $2 \mathrm{~s}$. Time steps of $3 \mathrm{~s}$ were used when radiation overtook conduction and became the dominant heat transfer mode. Once the flow was turned off, ten more days were needed to run the conduction-radiation problem to completion and simulate four to six hours of real-time.

To gain confidence in the solution, several studies were undertaken. A finer grid containing 360,000 cells (almost four times as many cells as the coarse grid) was developed and run for the first ten seconds of the pump-down. No significant changes in the predicted solution were observed. In addition, the flow solution for the coarse grid was run between $116 \mathrm{~s}$ and $118 \mathrm{~s}$ of real-time with different solver parameters. The time step independence was tested by using twice as small time steps $(0.02 \mathrm{~s})$ during that time period. No significant changes were observed on the crystal temperatures whether a $0.04 \mathrm{~s}$ time step or a $0.02 \mathrm{~s}$ time step was used. The convergence criteria for the enthalpy and mass residuals were also tightened to $0.1 \%$ without observing any change in the predicted temperatures. The number of rays emanating from each surface panel was increased from 36 to 144 without significant effects on the predicted results. The radiation zones were also increased from 1,850 zones to 4,014 zones (by using a maximum of $3 \times 3 \times 3$ cells per zone instead of $4 \times 4 \times 4$ cells) and no significant changes in the solution were observed.

Note that the problem was run in double precision because of the very small temperature differences. 


\section{Results}

The Optics Module pump-down flow solution is run for the first 2 min $52 \mathrm{~s}$. At this time, convection and radiation are of the same order of magnitude; and the temperature of the THG and the final lens are barely decreasing $\left(0.0001^{\prime \prime} \mathrm{C}\right.$ per second), while the temperature of the SHG is starting to increase back up. The flow solution is then turned off and a conduction-radiation run is started to simulate the recovery time of the optics.

Figures 6 and 7 show velocity contours and temperature field on a vertical plane passing through the outlet at $1 \mathrm{~s}, 40 \mathrm{~s}, 80 \mathrm{~s}$, and $120 \mathrm{~s}$ of a 10 minute pump-down, respectively.

Initially, the flow is forced-convection dominated while air is being pulled out through the outlet. At first, the temperature field inside the Optics Module is very uniform. The gas begins to cool slightly because of the expansion process, but the optics have not cooled down yet.

After the first $5 \mathrm{~s}$, the flow becomes free-convection dominated. The temperature difference between the gas and the crystals rapidly increases, inducing buoyant flow along the walls of the Optics Module housing and the FOC frame (see Fig. 8) and causing a chimney effect in the corner channels of the FOC (see Fig. 9). The average gas temperature reaches a minimum of $266 \mathrm{~K}$ at $40 \mathrm{~s}$. At that point, the optics are cooling down steadily and the SHG crystal has already cooled down by $0.14^{\circ} \mathrm{C}$. The pressure has almost dropped by a factor of two (see Fig. 10). The air progressively warms up as it circulates along the warmer walls of the Optics Module housing and the FOC frame. At $80 \mathrm{~s}$, the average air temperature has increased by $10^{\circ} \mathrm{C}$ from its minimum temperature and is about $3^{\prime \prime} \mathrm{C}$. The gas located below the final lens is stagnant and, therefore, tends to warm up more slowly than the air in the upper part of the Optics Module since it is blocked by the FOC.

Figure 10 shows the pressure distribution in the Optics Module at $1 \mathrm{~s}, 40 \mathrm{~s}, 80 \mathrm{~s}$, and $120 \mathrm{~s}$ during the pump-down process. The pressure field is seen to be uniform throughout the pumpdown. This implies that the corner channels are large enough not to create any pressure gradients across the optics. The maximum pressure differential across an optic is about $10 \mathrm{~Pa}$.

The average temperature of the optics over a time period of four hours after a 10 minute pump-down is shown on Fig. 11. All three optics do not cool down at the same rate. The uppermost crystal (SHG) is cooling down faster since it sees cooler air on its upper surface. In addition, the gas rises freely above the SHG, inducing buoyant flows that enhance convection. The THG crystal gives off very little heat to the gas that surrounds it as the gas located in the 
small volumes in between the optics remains warm throughout the pump-down process (see Fig. 7). The gas located in these volumes does not mix very well with the cooler gas outside of the FOC since it is trapped between two warm optics and has to exit through the corner channels to mix with the cooler air. The final lens is cooling even slower than the middle crystal since its thermal mass is about twice that of the THG crystal.

The SHG crystal is warming faster than the other optics since its upper surface "sees" primarily the walls of the Optics Module housing as well as the vacuum window, which are warmer and maintained at $20.00^{\circ} \mathrm{C}$. The average temperature of the SHG crystal returns to operating temperature after 45 minutes. However, while the optics temperature is relatively uniform 45 minutes after the pump-down begins, in-plane temperature gradients across the optics begin to develop at that time. These temperature gradients develop because the FOC frame, initially warmer than the SHG crystal, does not warm up to ambient temperature as fast as the optics because of its low emissivity (0.02). Figure 12 shows temperature contours in a horizontal section across the Optics Module at a vertical location corresponding to the upper surface of the SHG crystal at 49 minutes, two, three and four hours after the beginning of a 10 minute pumpdown. The temperature differential across the SHG crystal peaks at $0.073^{\circ} \mathrm{C}$ after about two hours and decreases slowly thereafter. After four hours, the temperature differential is still $0.047^{\circ} \mathrm{C}$. These temperature gradients are likely to be reduced significantly if a higher emissivity for the FOC frame is used.

\section{Concluding Remarks}

The CFX model indicates that the average temperature of the KDP crystals will recover to $0.1^{\circ} \mathrm{C}$ of the operating temperature within 45 minutes.

Because of machine CPU speed limitations, the CFX pump-down model has not proven to be the versatile design tool we hoped for. Nevertheless, this detailed 3-D model provided us with useful information regarding the recovery time of the crystals for a 10 minute pump-down. It also gave us a better understanding of the effect of the FOC frame emissivity on the optics recovery time.

A simpler lumped-capacitance model is under development using the network type fluid/thermal simulator, SINDA/FLUINT. This model should be able to capture the general cooling trend of the optics without the long running time of the full-physics 3-D model. It features several improvements from a similar model developed during Title I. This new model 
includes all the optics components and simulates conduction from the optics to the FOC frame. Radiation exchange factors are calculated based on the CFX model geometry. Preliminary studies to calibrate the SINDA model are underway; the full-physics CFX model is used to calibrate the heat-transfer coefficients used in the SINDA model. The SINDA model is likely to serve as a more flexible design tool to predict the effects of longer pump-down rates or to perform sensitivity studies.

An FOA prototype testing project is now underway to supplement our calculations and aid in the design process. Information obtained during the analysis phase is being used to guide the FOA prototype experimental plan and to determine instrumentation. Prototype test results will be compared to results predicted by SINDA and CFX.

\section{VENTING MODEL}

\section{Grid and Boundary Conditions}

The grid for the venting model contains 105,000 cells (see Fig. 13). A discrete Shah radiation model with 3,754 zones was generated. A maximum of $3 \times 3 \times 3$ cells per radiation zone was used.

The boundary conditions used on all external walls for the venting model are the same as those used for the pump-down model. To simulate a 10 minute venting, the pressure is ramped up linearly at the inlet from $100 \mathrm{~Pa}$ to atmospheric pressure.

\section{Problem Physics and Solver Parameters}

The physics of the problem are even more complicated than for the pump-down simulation. The flow is a 3-D, transient, fully compressible, laminar, buoyant flow of a perfect gas, but it is also a high-speed flow. The gas properties vary with the temperature within each grid cell. All modes of heat transfer are taken into account. Double precision was also used to run the venting simulation.

The convergence criterion used was that the sum of the mass (enthalpy) residuals over the mass (enthalpy) leaving the system had to be less than $5 \%$. To satisfy this criterion, time steps of $0.01 \mathrm{~s}$, with an average of 30 iterations per time step, were used in this study. Because the time step that the code was able to take was even smaller than the time step used to run the pumpdown problem (two to four times smaller), we were only able to simulate the first $20 \mathrm{~s}$ of a 10 minute venting. It took 7 weeks of CPU time on a Silicon Graphics Onyx computer with $1 \mathrm{~Gb}$ of 
RAM and $90 \mathrm{MHz}$ R8000 processors to run those first $20 \mathrm{~s}$. Note that the more restrictive $1 \%$ convergence criterion previously used for the pump-down calculation would have required even smaller time steps, which was not feasible.

\section{Results}

Figures 14, 15 and 16 show velocity and temperature contours on a vertical plane passing through the inlet at $0.25 \mathrm{~s}, 4 \mathrm{~s}, 11 \mathrm{~s}$, and $20 \mathrm{~s}$ of a 10 minute venting. The gas expands into the chamber as it sees a lower pressure and forms a thin high-speed jet across the Optics Module as shown on Fig. 14. The gas Mach number increases, peaks at 1.45 about fours seconds after the beginning of the venting, and decreases thereafter. Away from the jet, the velocities are relatively low (see Fig. 15); thus, it is recommended that the inlet port be located as far away from the FOC as possible. The high-speed jet is impinging on the back wall, warming up the wall locally because of compression and gas stagnation as shown on Fig. 16. As the gas is bled into the evacuated chamber, its temperature first rises to $310 \mathrm{~K}$, and then drops rapidly as heat is removed by the conditioned Optics Module walls. At $20 \mathrm{~s}$, the average gas temperature has returned to about $301 \mathrm{~K}$. The optics warm up very slowly. At $20 \mathrm{~s}$, the temperature of the SHG crystal has only increased by about $0.01^{\circ} \mathrm{C}$. The THG and the final lens are warming slower than the SHG crystals as they are in contact with cooler air (they are warming up slower for the same reasons that they are cooling down slower during pump-down). Convection has a minimal impact on the crystal temperatures since the gas has a very low density (about 0.02 to 0.04 $\left.\mathrm{kg} / \mathrm{m}^{3}\right)$, and this explains why the optics are warming up so slowly.

\section{Concluding Remarks}

Because of problem complexity as well as tight convergence criteria, very small time steps (smaller than in the pump-down simulation) had to be taken to simulate a 10 minute venting process, making this simulation impractical using available machines. We do not recommend running this simulation further, but rather we suggest to rely on prototype experiments to define the venting thermal upset and recovery.

It is not possible to fully simulate a few seconds' fast-venting process because the pressure ratio that CFX can handle across the inlet cannot exceed 100, which could correspond to Mach numbers above 5 . Furthermore, to properly calculate a solution with a pressure difference across the inlet of this magnitude requires a very fine grid and time steps of the order of microseconds. 
However, to evaluate the thermal upset caused by a fast-venting process using CFX, we can make the approximation that the venting occurs so fast that the crystals do not have time to warm up and that the gas does not have time to cool down (adiabatic process). For this run, the optics are set to ambient temperature $(293.15 \mathrm{~K})$ initially. The gas is assumed to be quiescent; its temperature corresponds to the temperature of a gas undergoing an adiabatic compression from vacuum to atmospheric pressure $(410.41 \mathrm{~K}$, if the temperature of the gas which is bled into the evacuated tank is $293.15 \mathrm{~K}$ ). This simulation is currently running; results will be available soon. Note that since the flow is assumed to be initially quiescent, all the convective effects associated with the high-speed flow are neglected and therefore the warm up of the crystals may be underestimated. On the other hand, the warm up may be overestimated if the actual gas temperature does not reach the adiabatic compression value.

\section{REFERENCES}

Patankar, S. V., 1980, Numerical Heat Transfer and Fluid Flow, McGraw-Hill, NY.

Roth, A., 1982, Vacuum Technology, Elsevier Science Publishers B.V., Amsterdam, The Netherlands.

Shah, N. G., 1979, "New Method of Computation of Radiation Heat Transfer in Combustion Chambers," Ph.D. thesis, Imperial College of Science and Technology, London, England.

Van Doormal, J. P., and Raithby, G. D., 1984, "Enhancements of the SIMPLE Method for Predicting Incompressible Fluid Flows," Num. Heat Trans., Vol. 7, pp.147-163. 


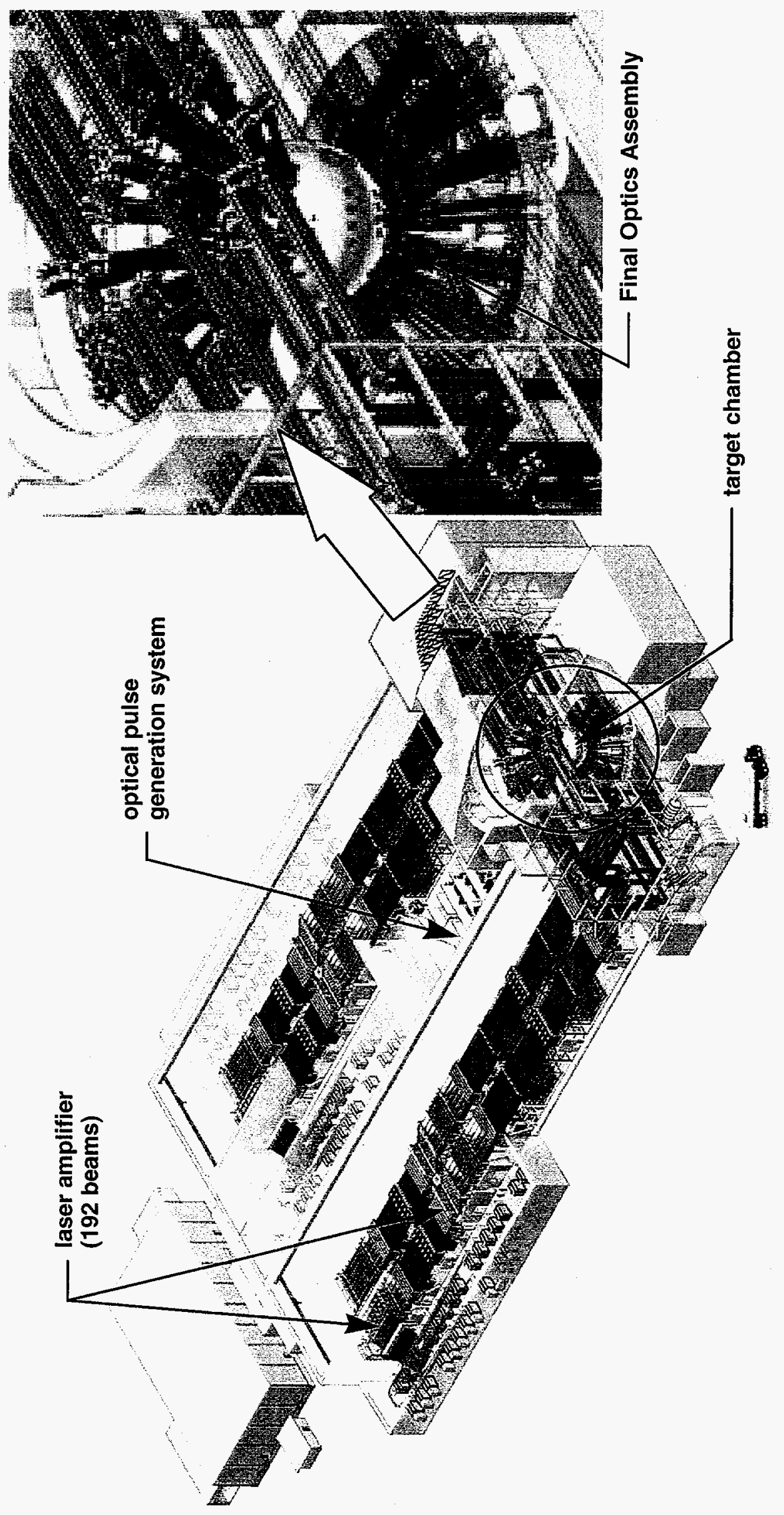

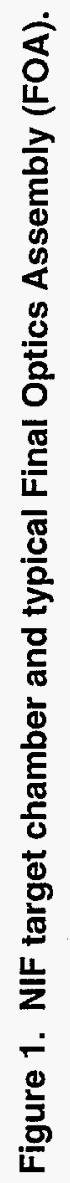




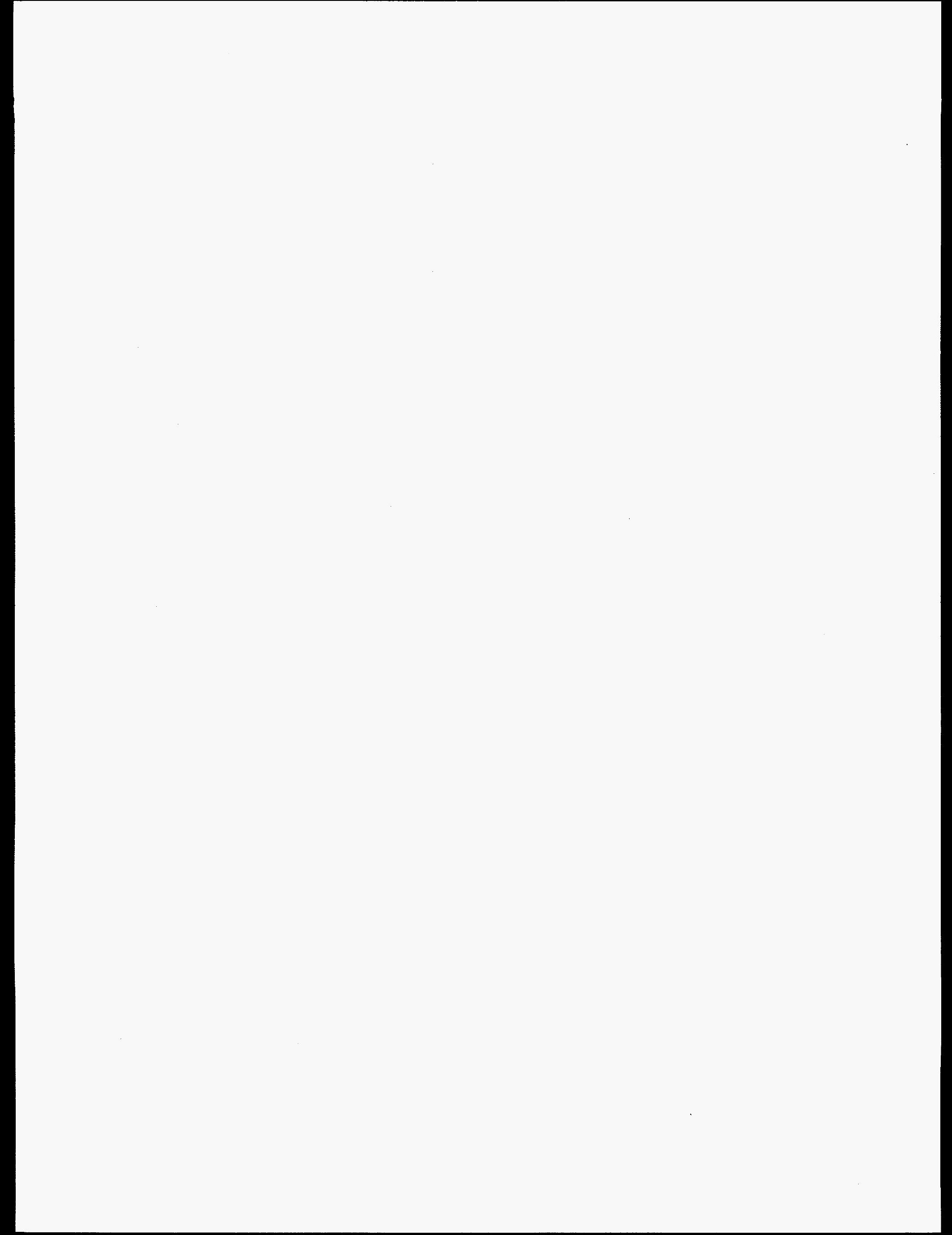



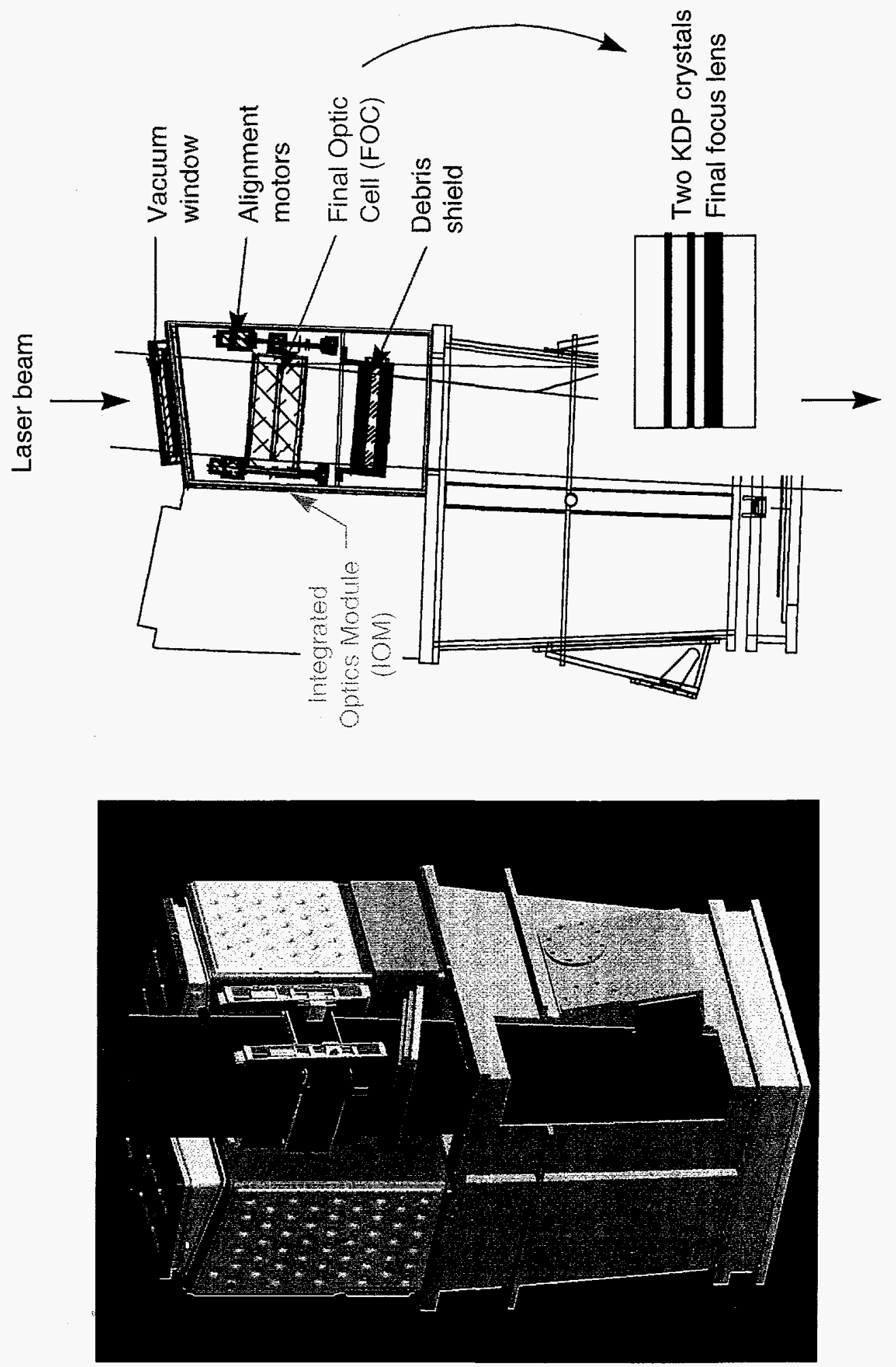

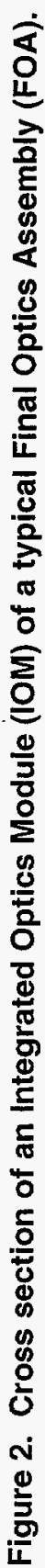





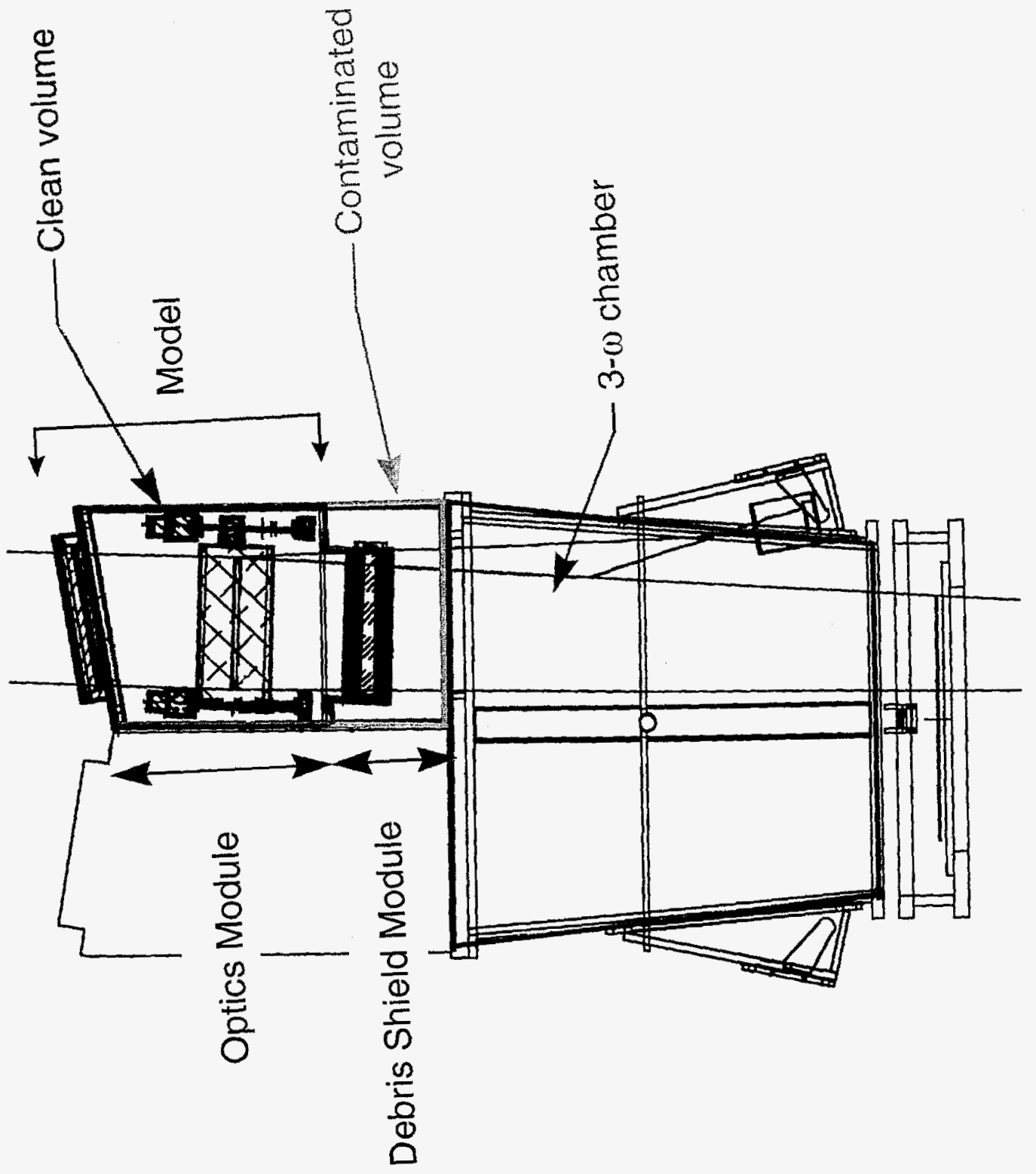

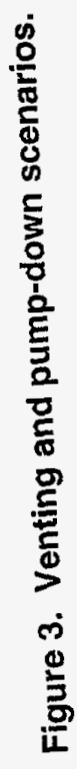





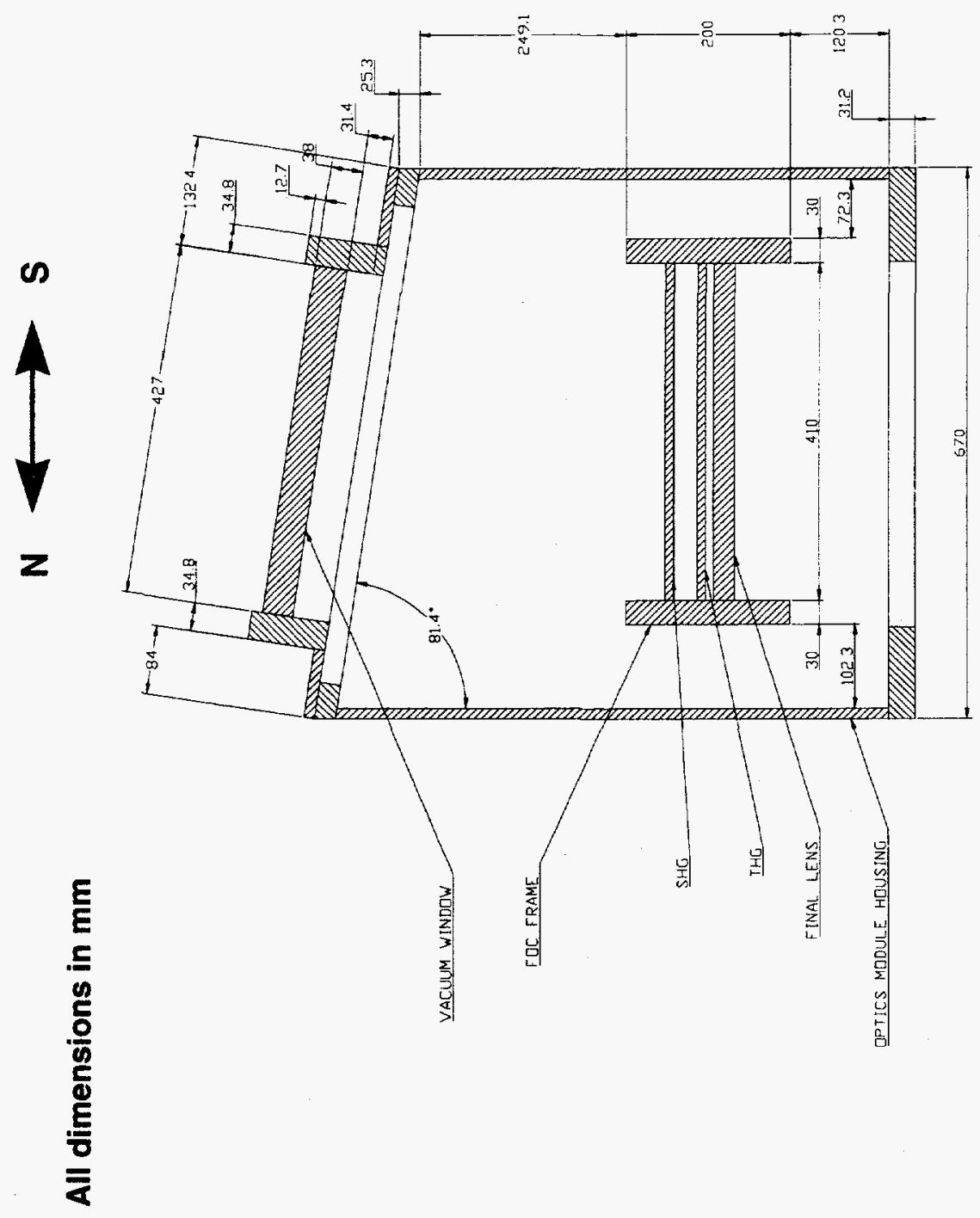

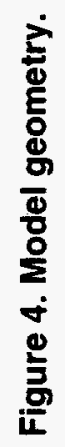

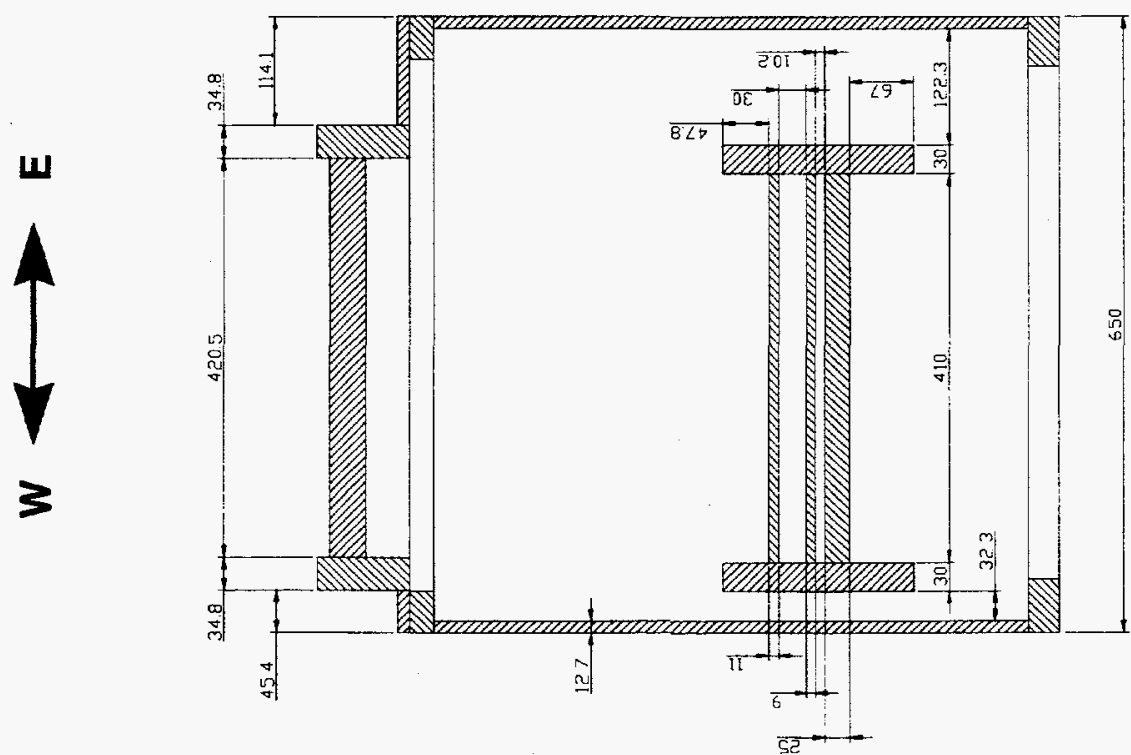





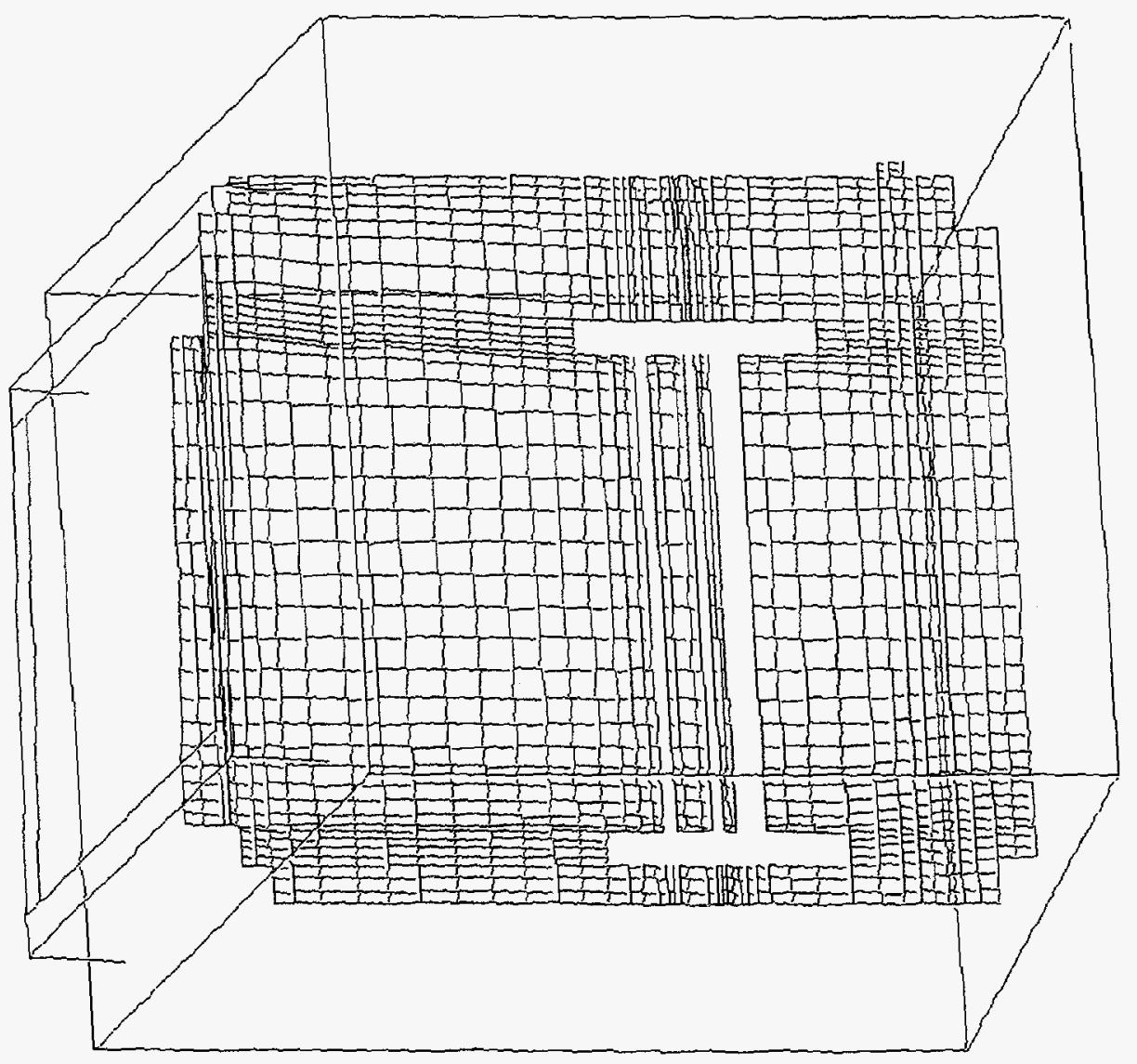

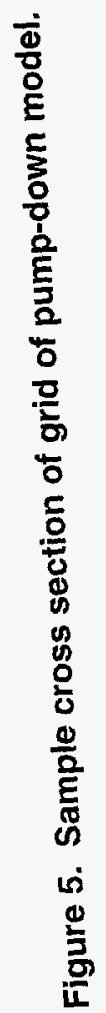




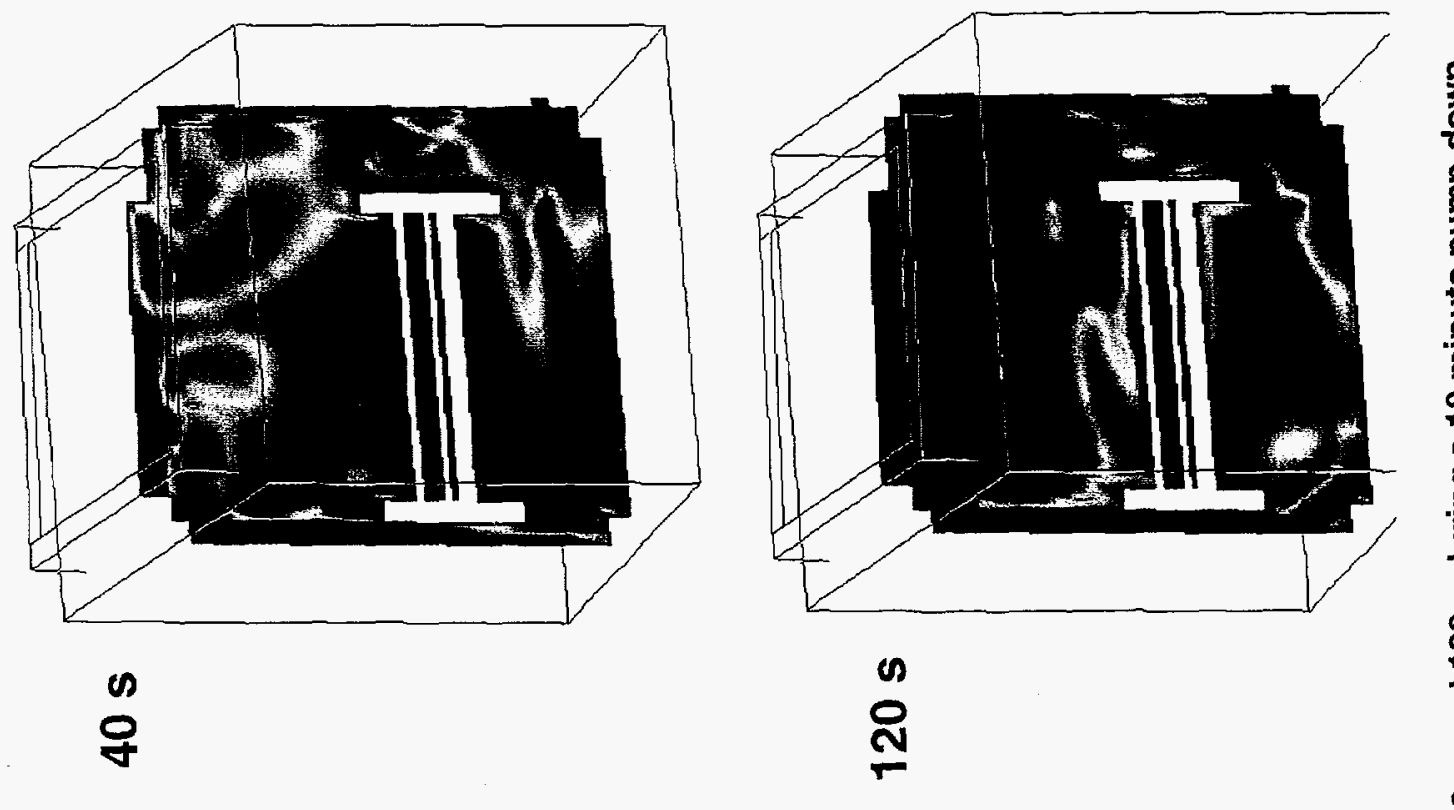

$\begin{array}{lllllllll}E & 0 & 0 & 0 & n & m & 0 & \dot{0} & 0 \\ \dot{0} & 0 & 0 & 0 & 0 & 0 & 0 & 0 & 0 \\ \frac{0}{0} & 0 & 0 & 0 & 0 & 0 & 0 & 0\end{array}$

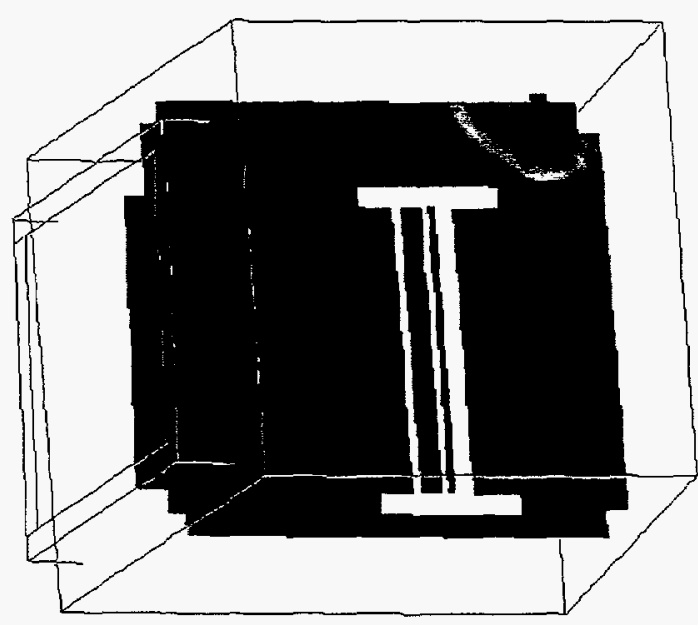

n

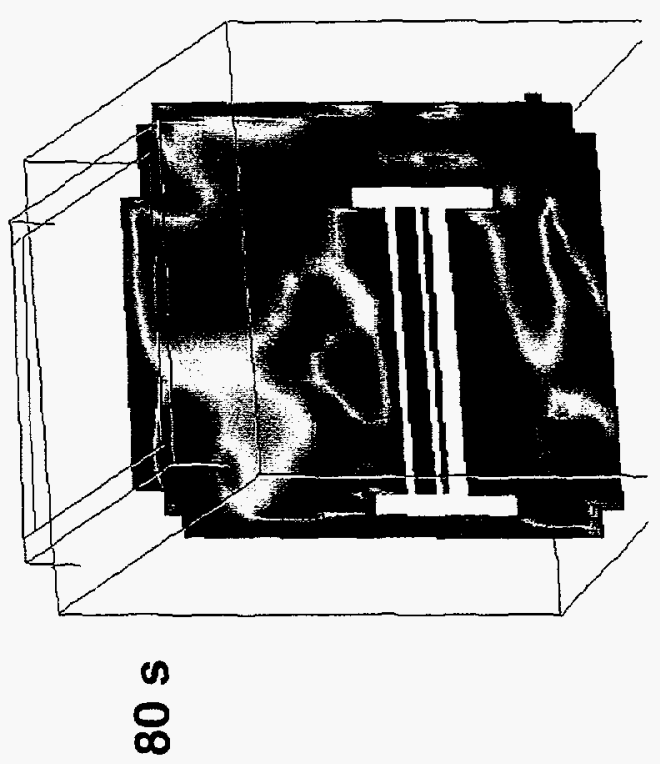

0 


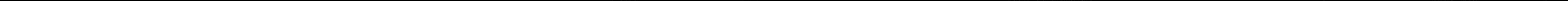



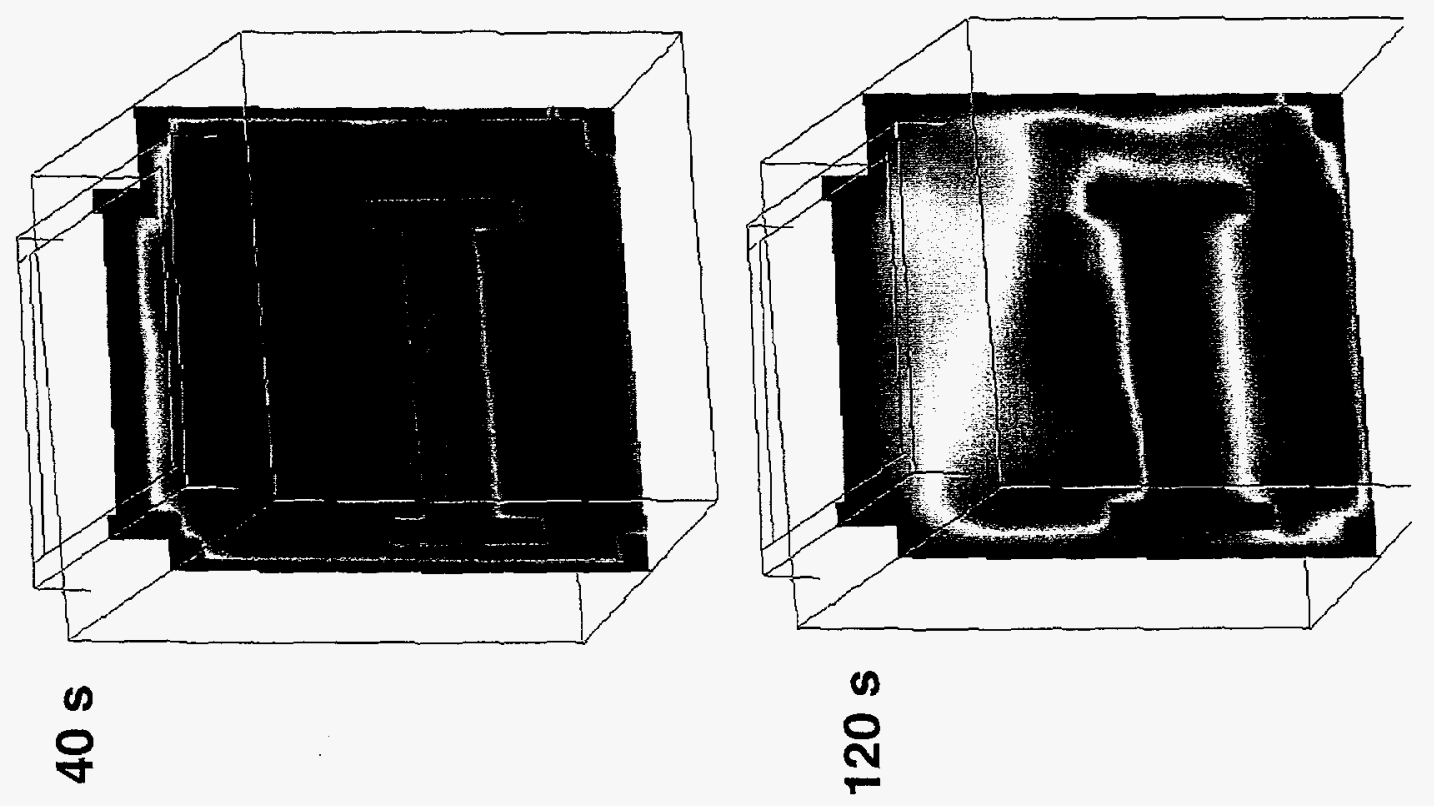



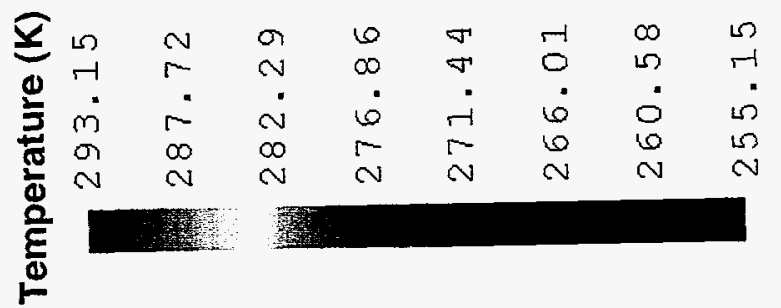

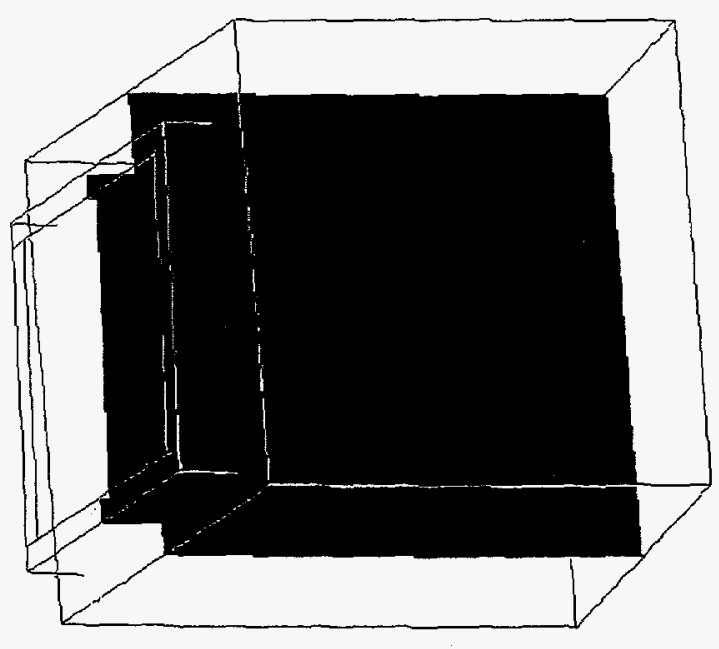

$\stackrel{\infty}{-}$

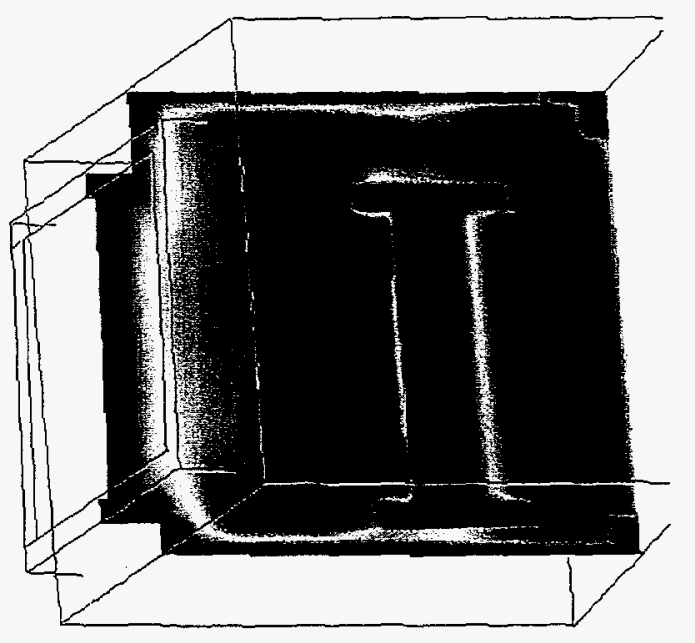

n

ஜ 



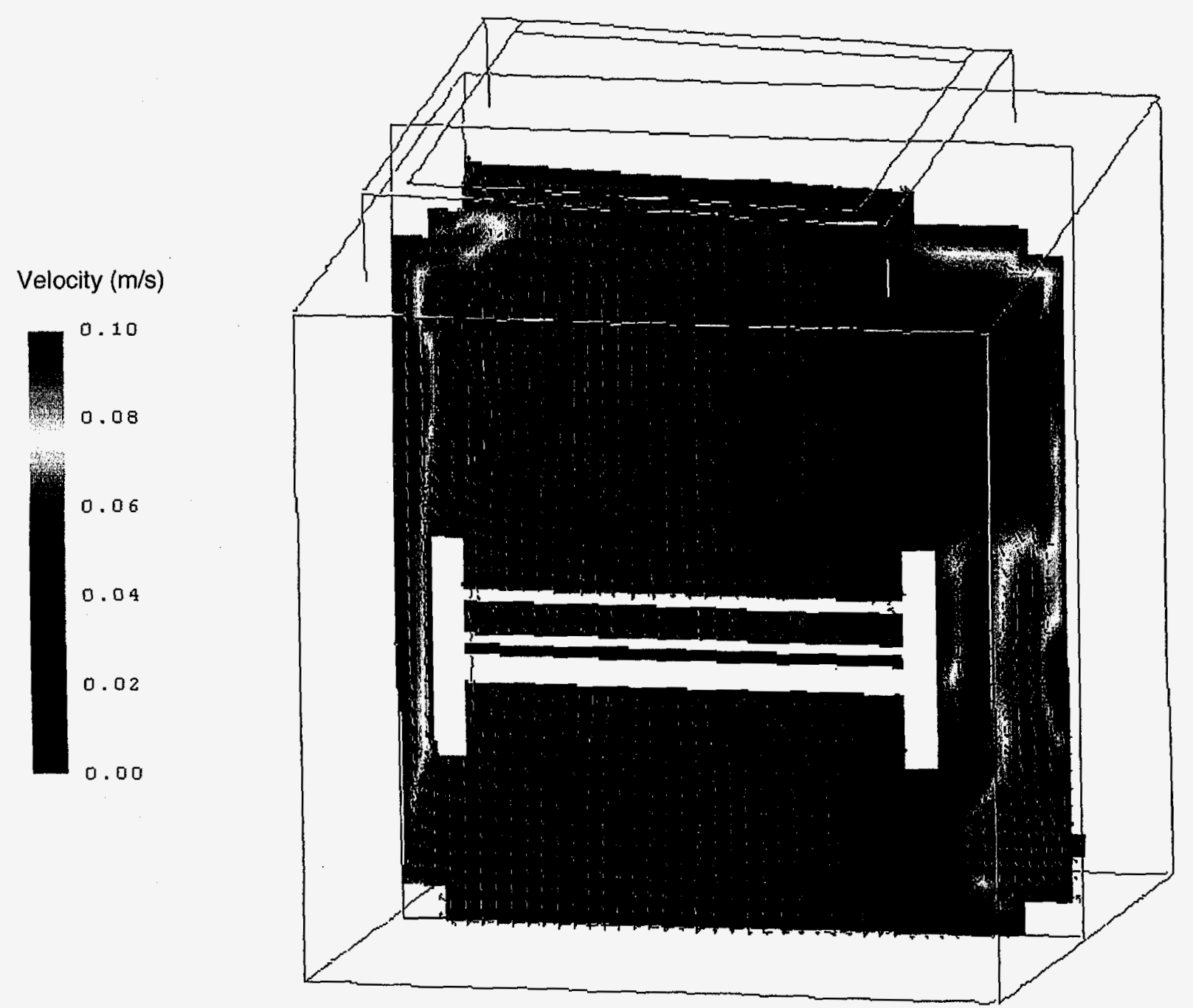

Figure 8. Flow field inside the Optics Module at $7 \mathrm{~s}$ during a 10 minute pump-down. 


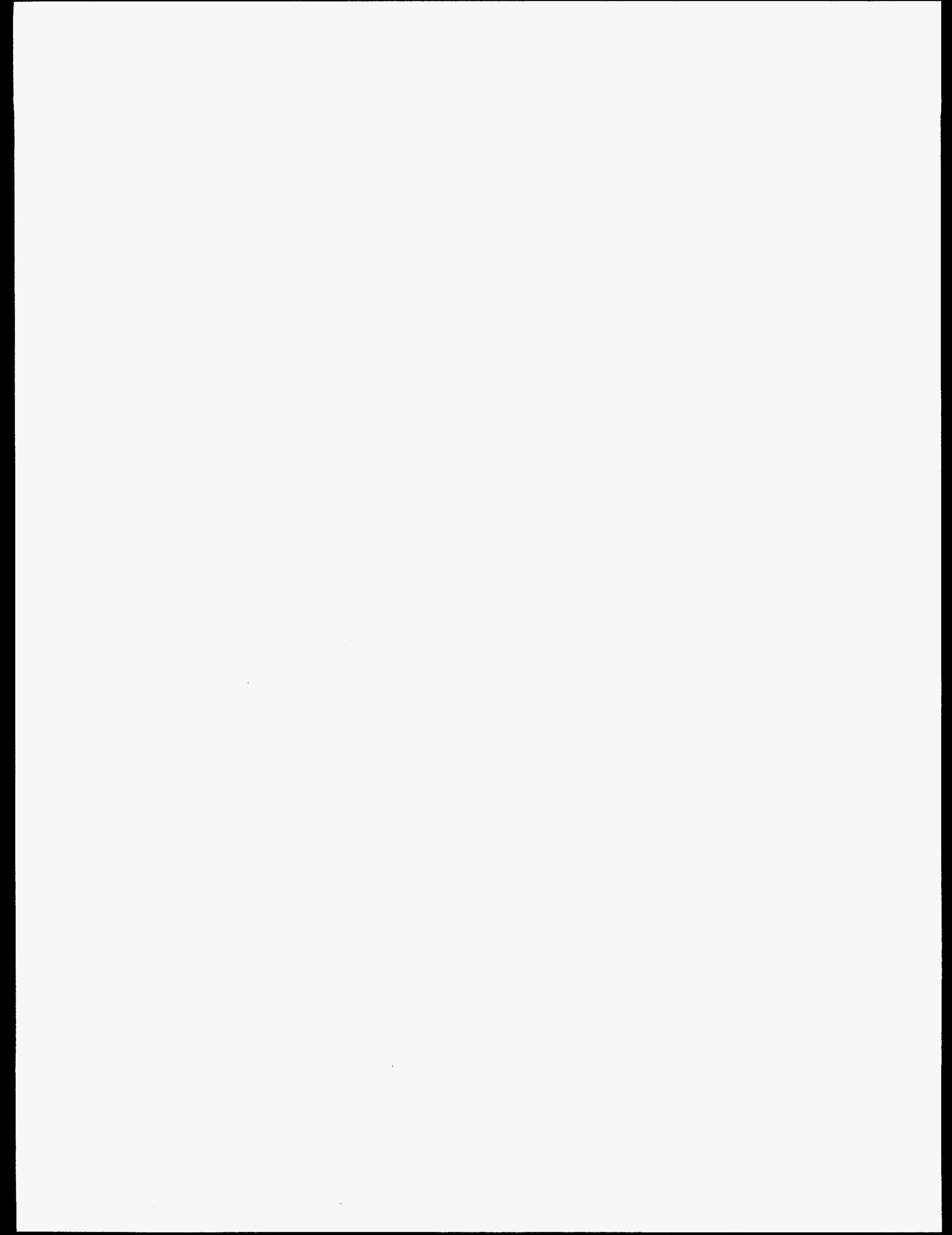



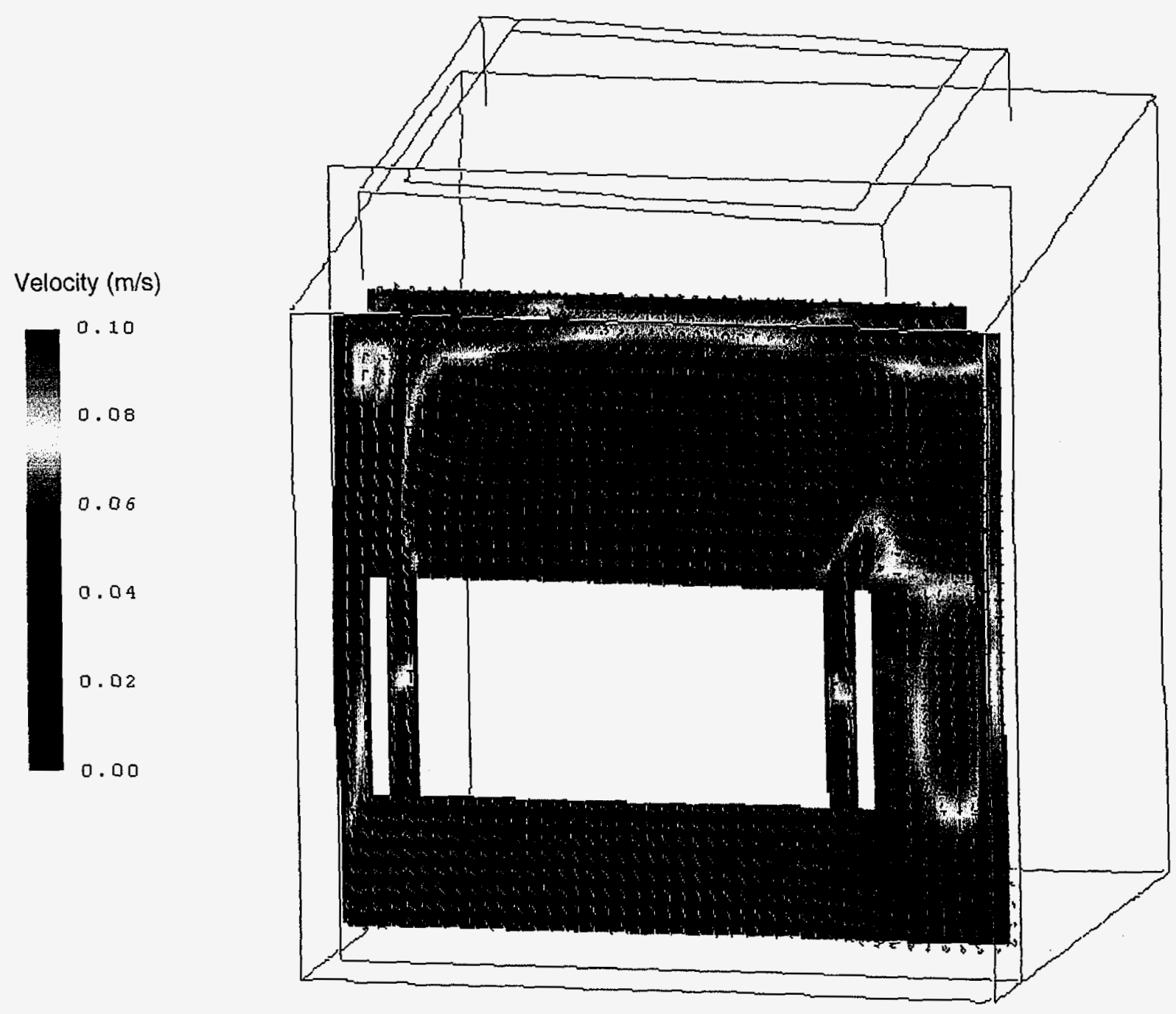

Figure 9. Flow field inside the FOC corner channels at $7 \mathrm{~s}$ during a 10 minute pump-down. 



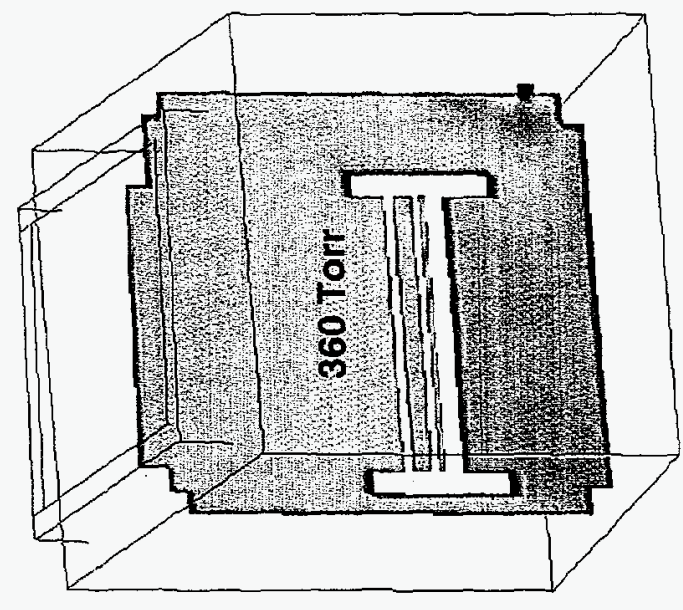

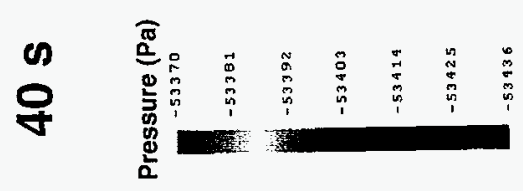

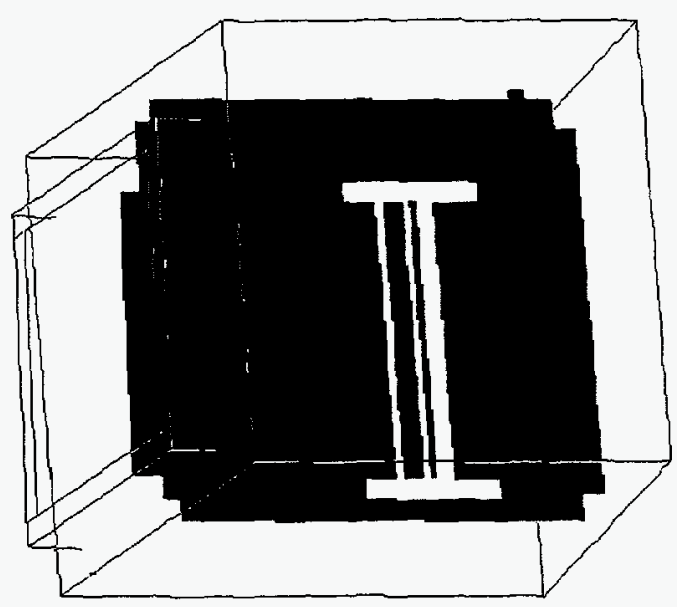

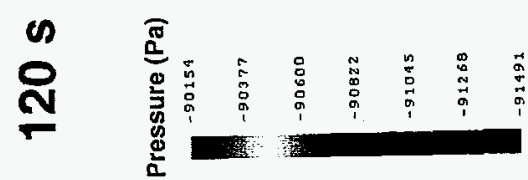

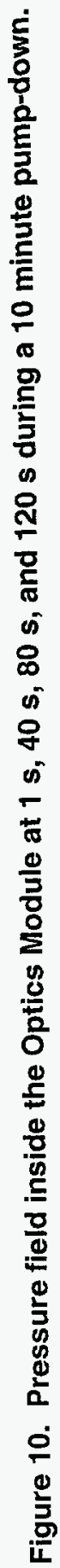

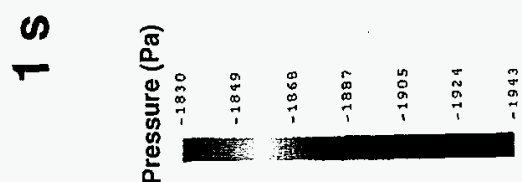

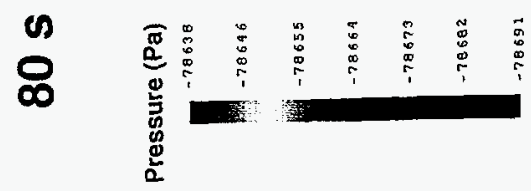




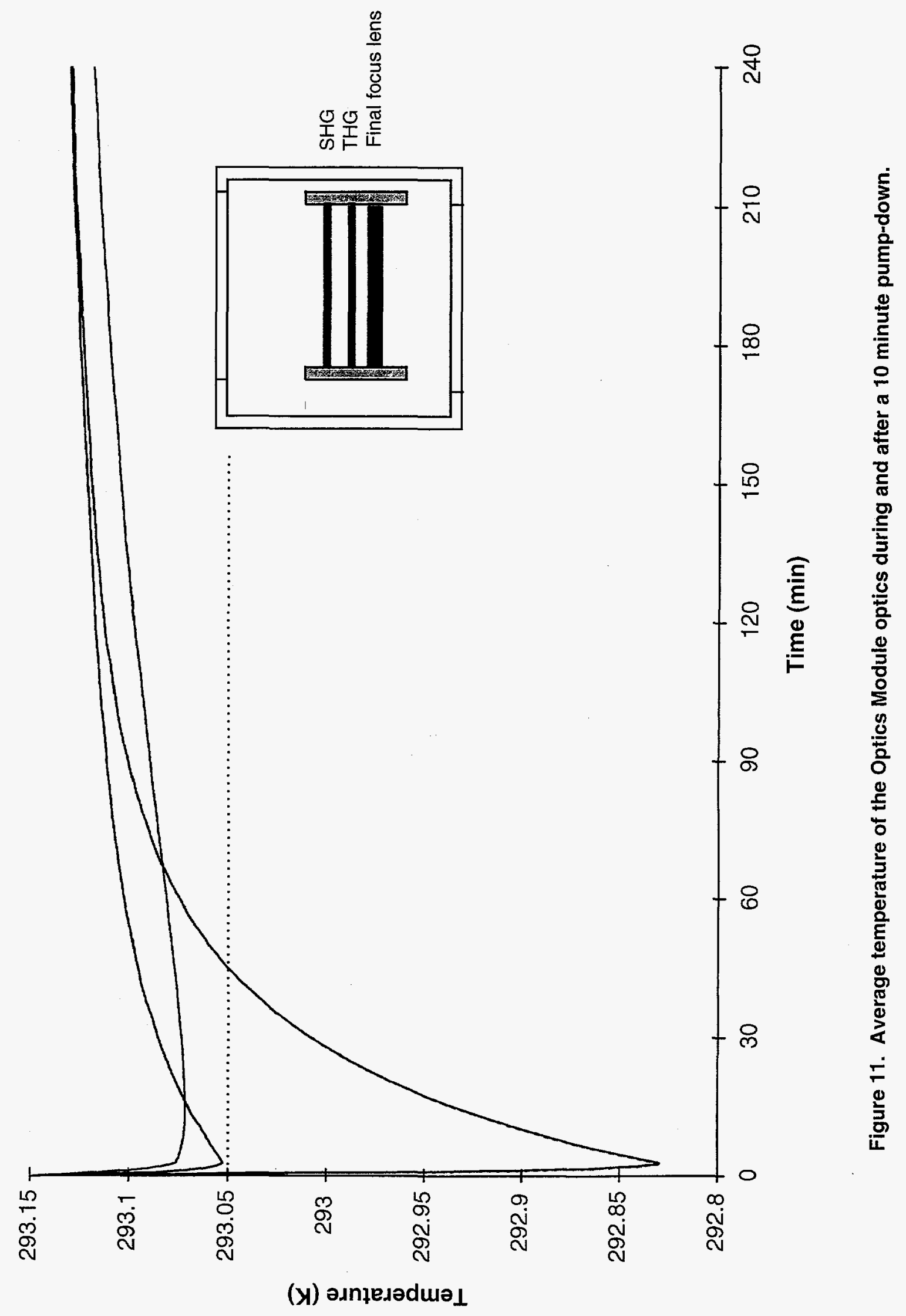




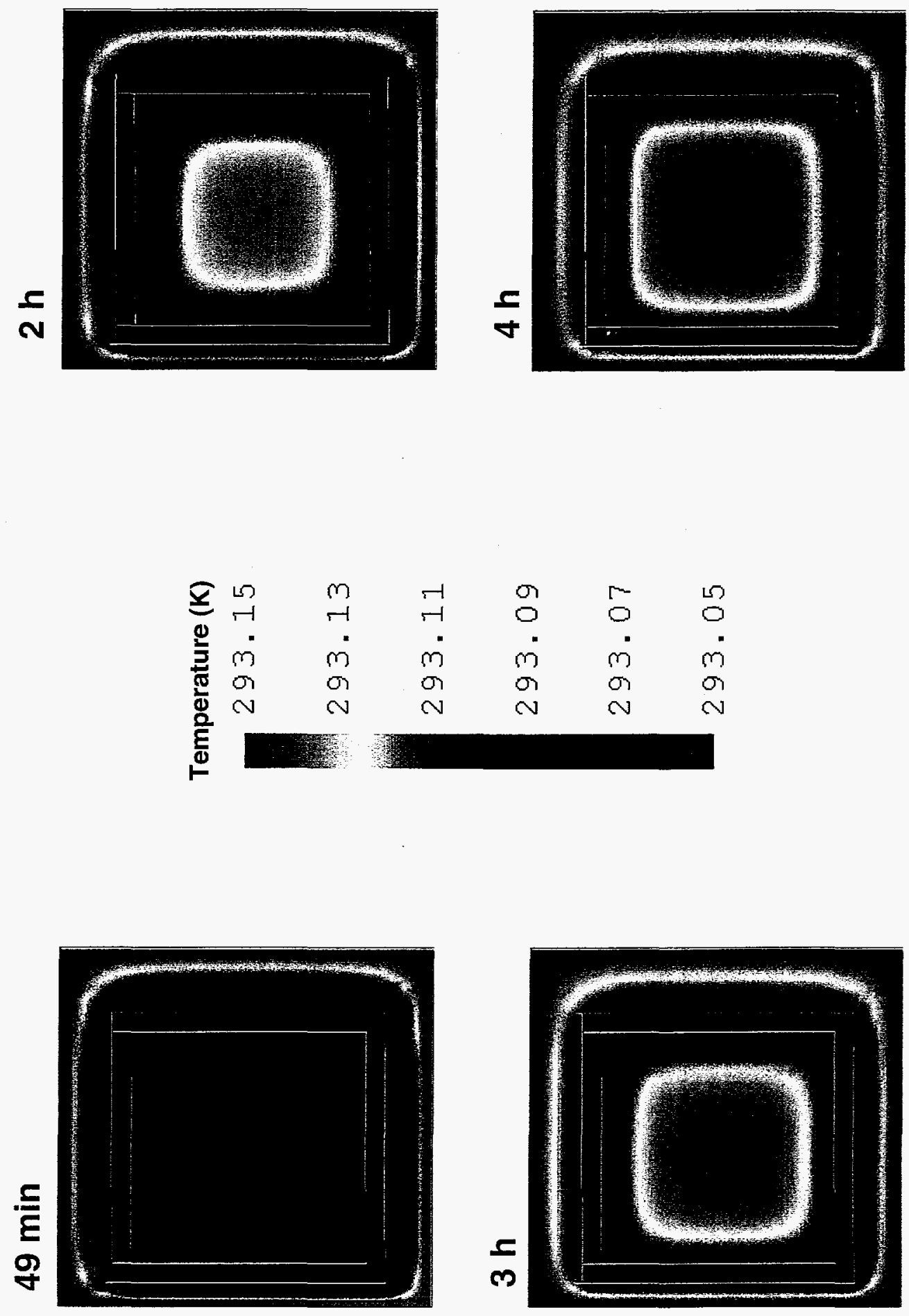

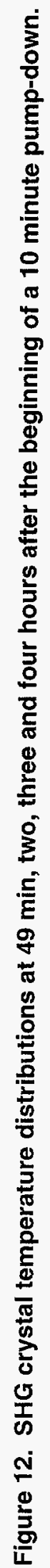




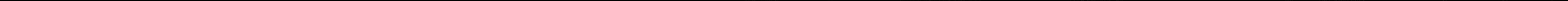




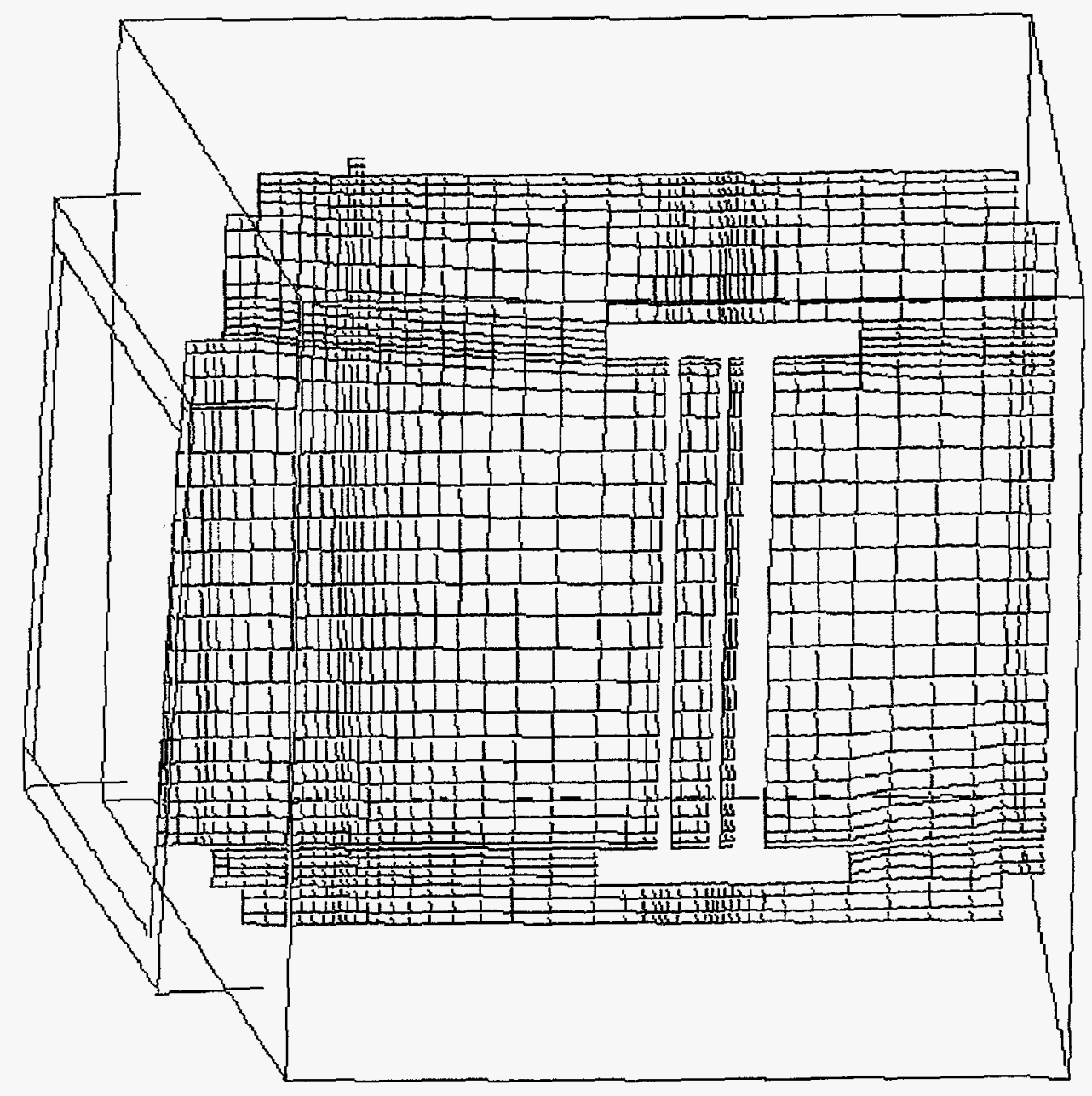

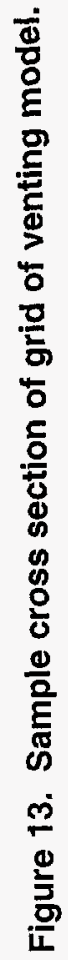




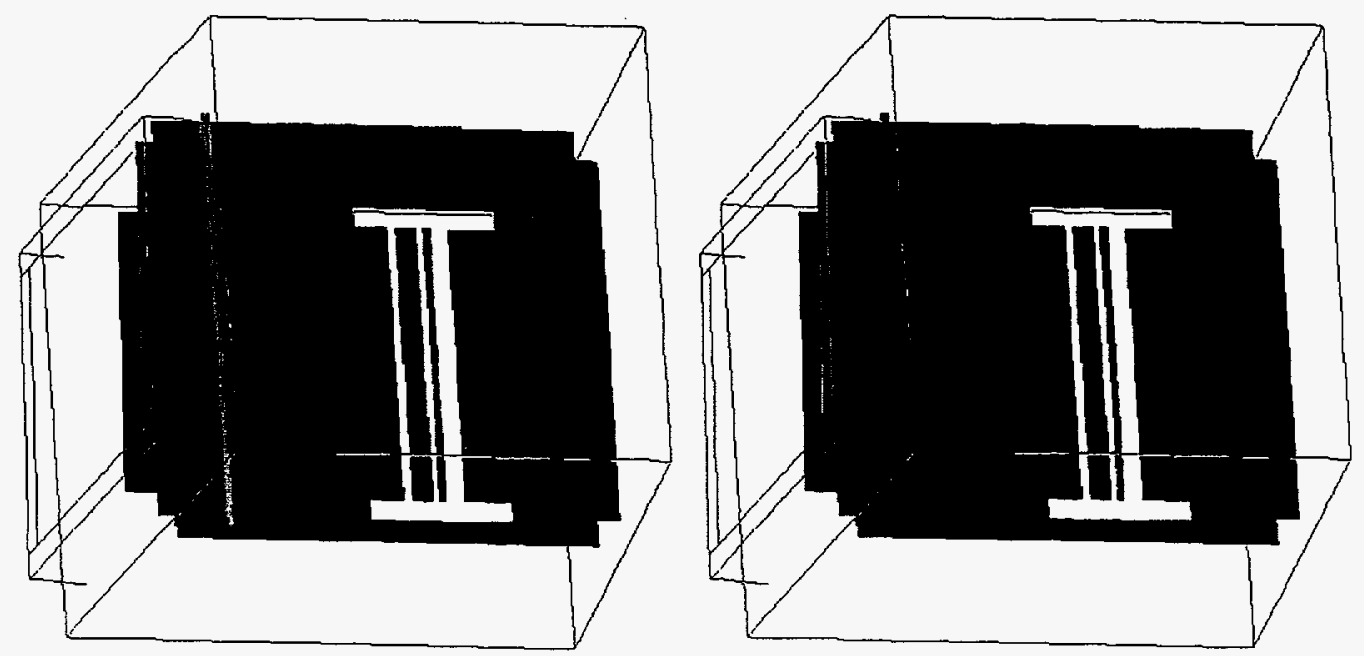

$\stackrel{n}{q}$
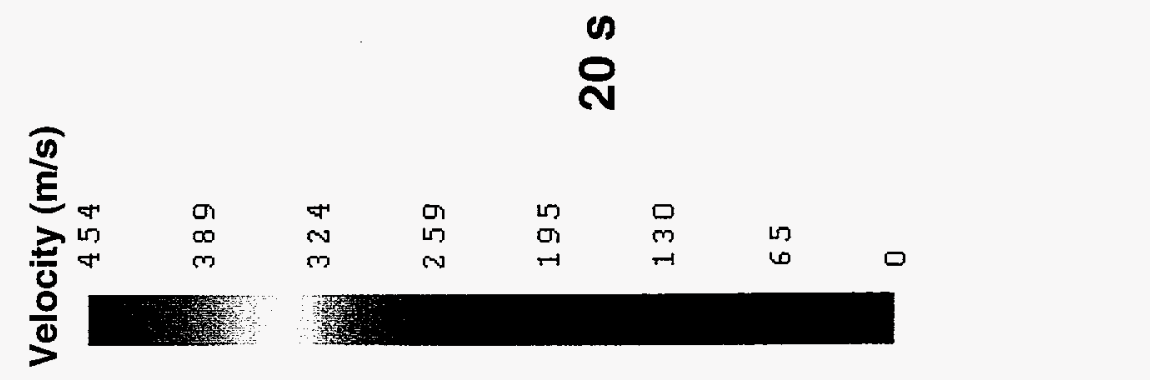

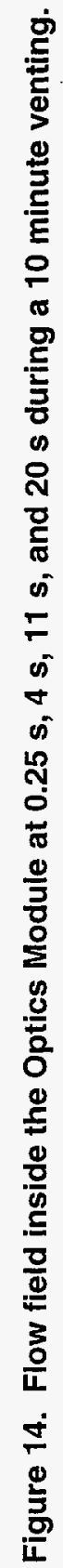

雚

$\stackrel{\infty}{=}$ 


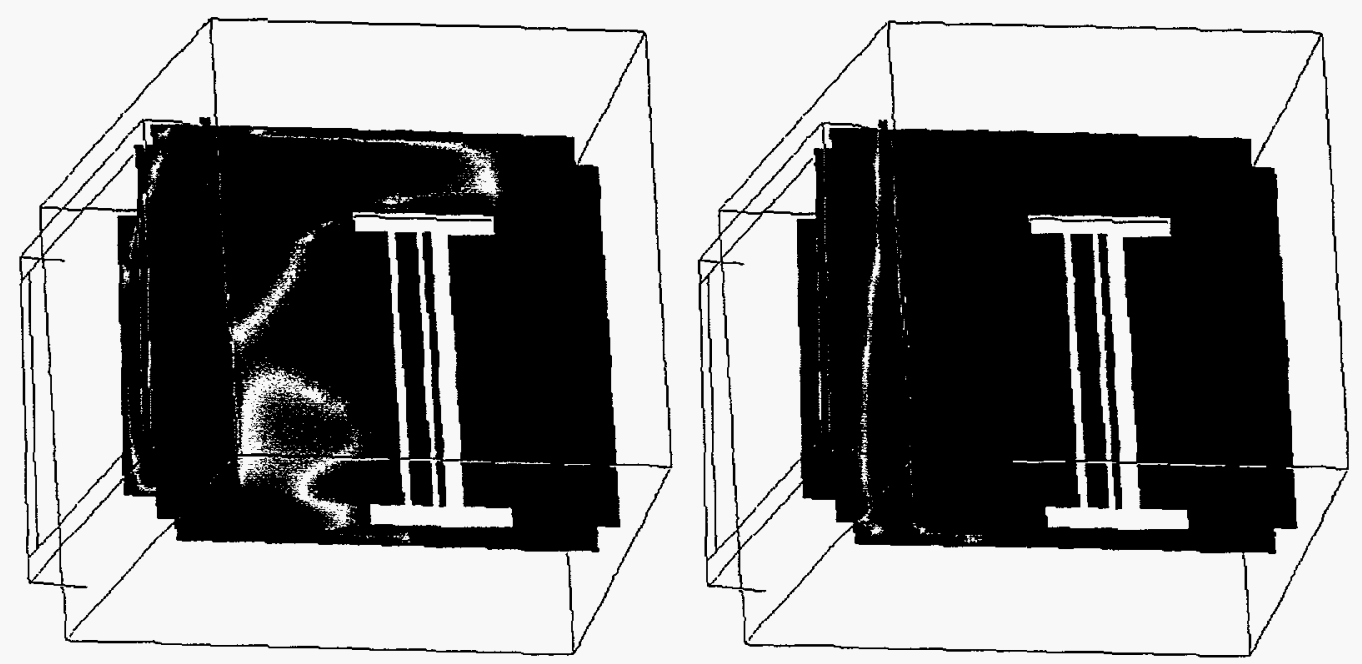

$\stackrel{0}{+}$
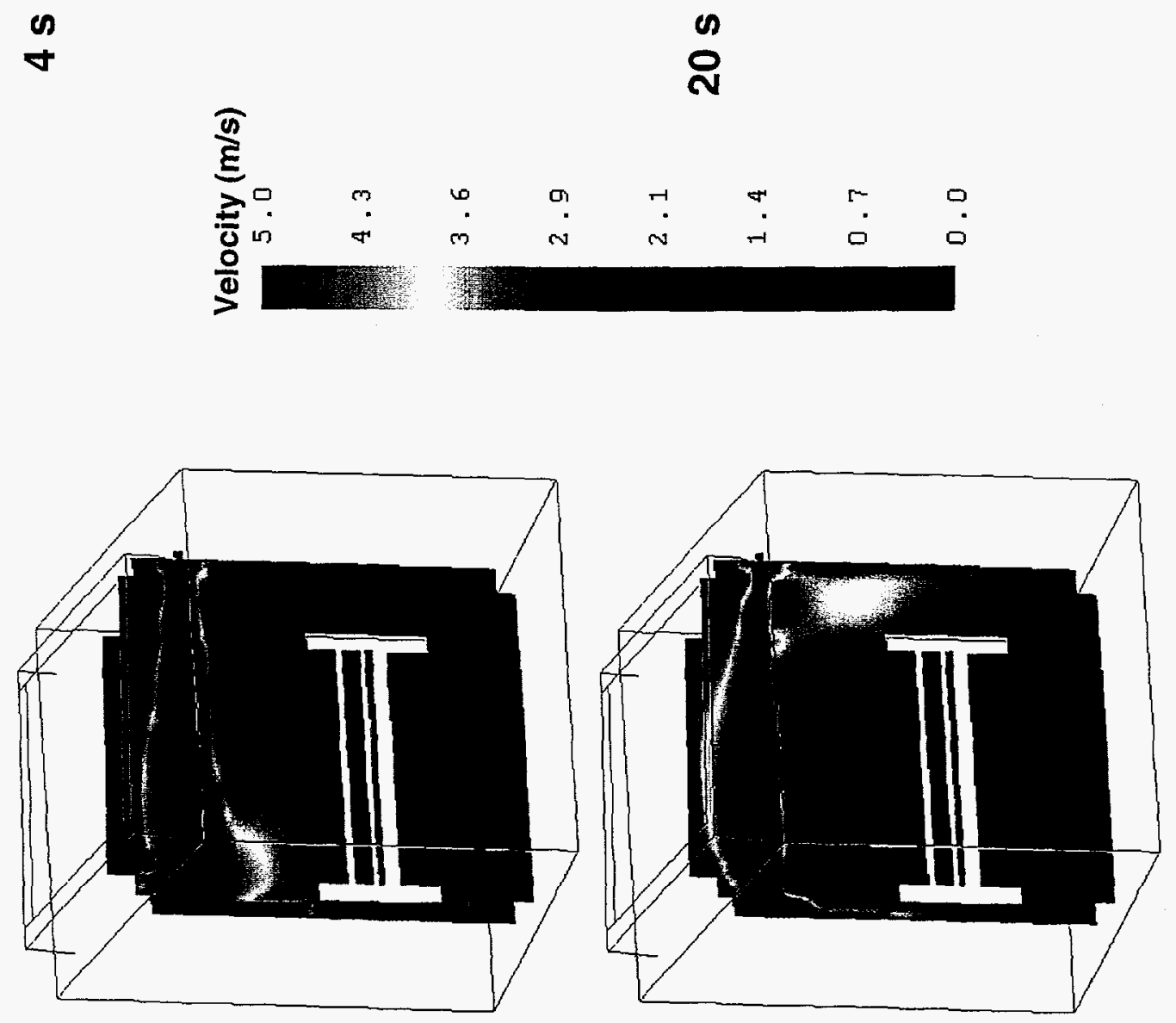

$n$
$\mathcal{Q}$
0

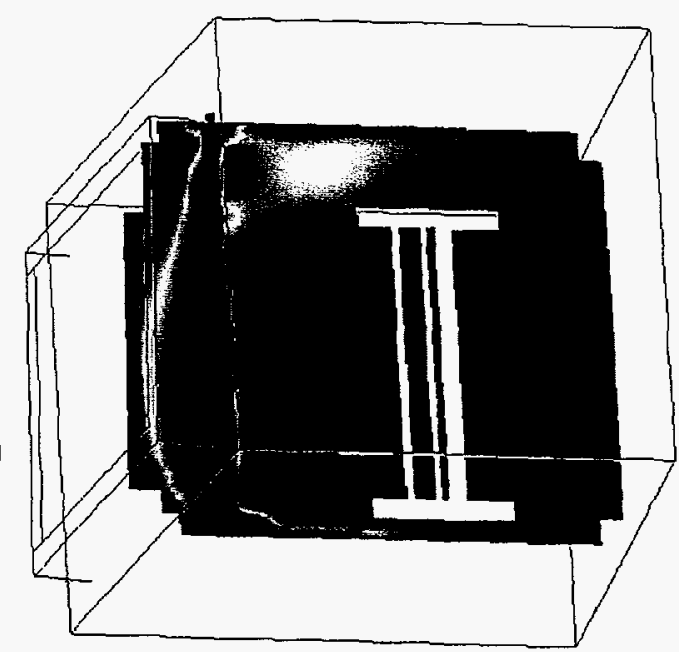

$\frac{\omega}{r}$

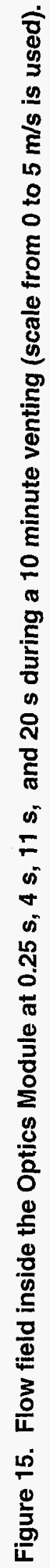




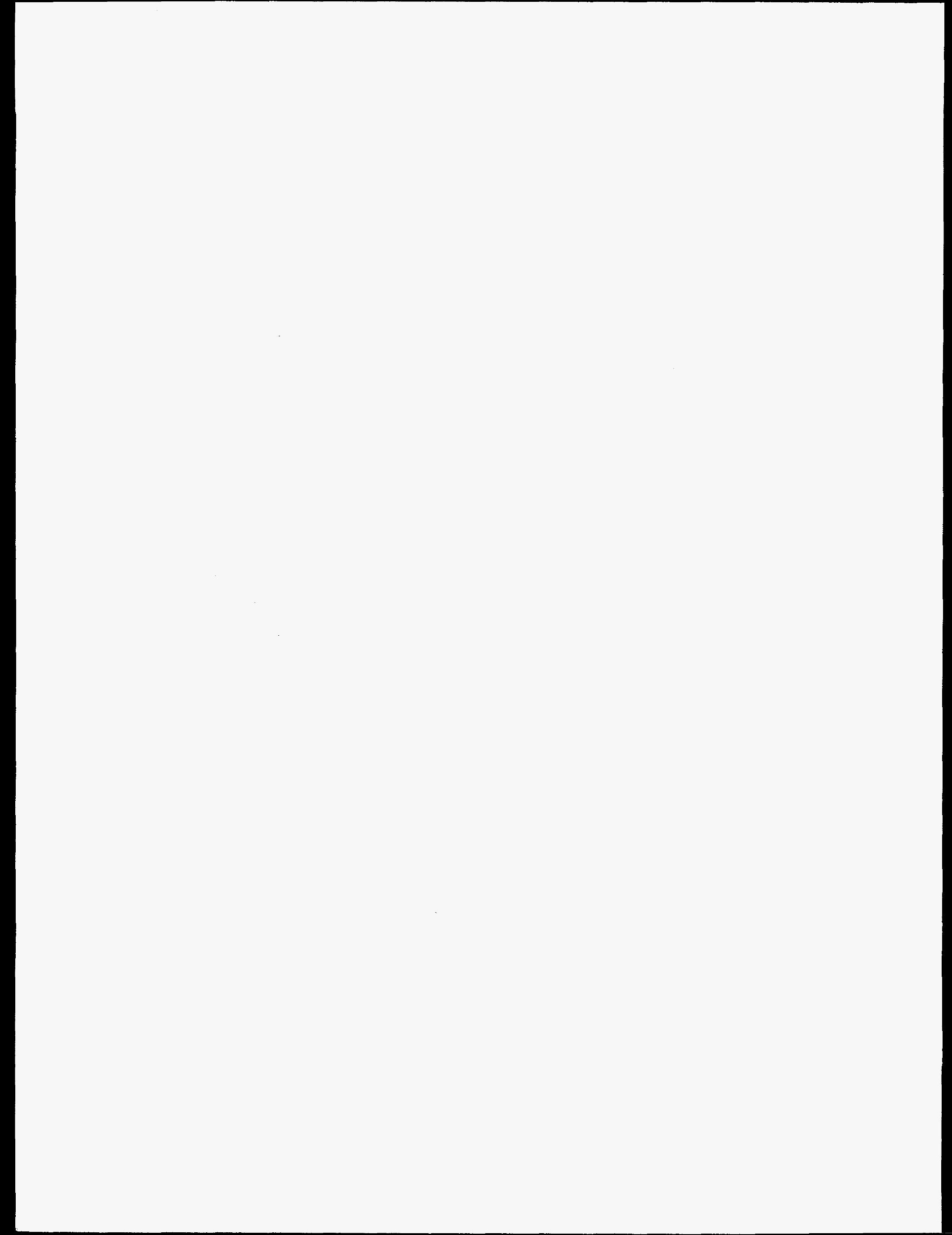



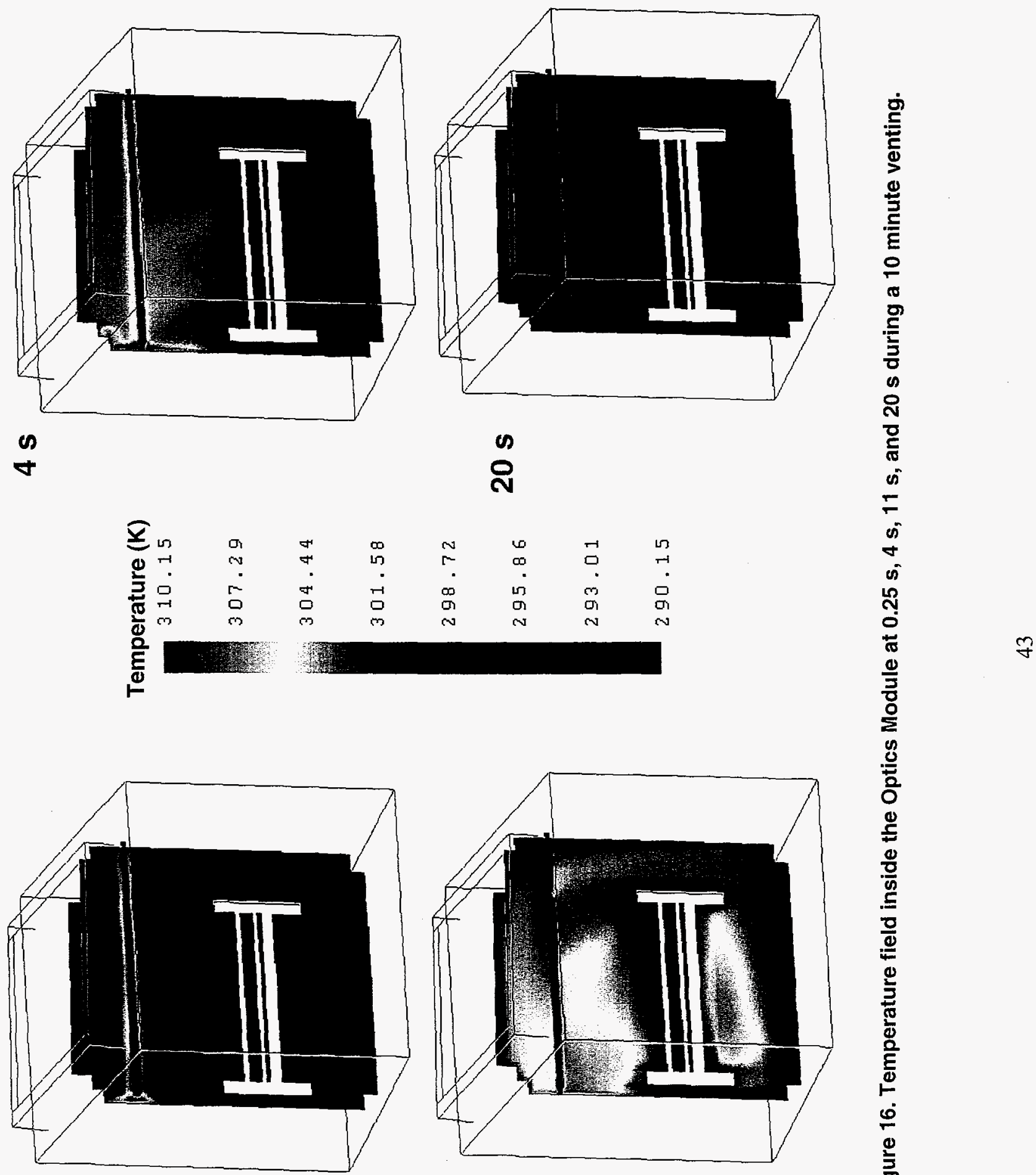

$n$
0
0
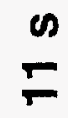